\title{
E-cadherin: Unexpected actor of invadopodia formation in pancreatic cancer
}

\author{
Aurélie Dobric ${ }^{1}$, Sébastien Germain ${ }^{1}$, Rénaté Bonier ${ }^{1}$, Françoise Silvy $^{1}$, Stéphane Audebert ${ }^{2}$, Luc Camoin $^{2}$, Nelson Dusetti ${ }^{1}$, \\ Philippe Soubeyran ${ }^{1}$, Juan lovanna ${ }^{1}$, Véronique Rigot ${ }^{1, \square}$, and Frédéric André ${ }^{1, \square}$ \\ ${ }^{1}$ Pancreatic Cancer Team, Centre de Recherche en Cancérologie de Marseille (CRCM), Institut Paoli-Calmettes, Aix-Marseille Université, Inserm, CNRS, 13009 Marseille, \\ France \\ ${ }^{2}$ Marseille Proteomics Platform, CRCM, Institut Paoli-Calmettes, Aix-Marseille Université, Inserm, CNRS, 13009 Marseille, France.
}

Invasion/metastasis axis is the major driver of cancer mortality. By maintaining tissue cohesion, E-cadherin is considered as a protective marker for tumoral progression. However, recent studies suggested that the appearance of hybrid epithelial-mesenchymal (E/M) cells still expressing E-cadherin is favourable for the establishment of metastasis. This hypothesis is consistent with the observation that most pancreatic ductal adenocarcinomas (PDAC) are invasive and express E-cadherin in primary tumour and metastases. By using a data constituted by a series of patient-derived xenografts (PDX) from the PaCaOmics multi-centric clinical trial, we show that E-cadherin expression is not associated with stages of the pathology, prognosis, and overall survival in PDAC. The role of E-cadherin in PDAC aggressiveness was tested both in vitro and in cancer cell implantation models. We show that E-cadherin is a key component of membrane protrusions implicated in the extracellular matrix remodelling and degradation, called invadopodia. Ecadherin downregulation in a pancreatic model of $\mathrm{E} / \mathrm{M}$ hybrid cells reveals that E-cadherin downregulates Arp2/3 complex expression. As this complex is essential for branched actin structure, E-cadherin depletion strongly impaired invadopodia formation. On the other hand, we demonstrate that E-cadherin interacts with the membrane protease MT1-MMP at the invadopodial membrane. E-cadherin could be recycled back to the invadopodial membrane simultaneously with MT1-MMP. Indeed, both Rab7 vesicle-dependant and/or a Rab11 vesicledependant pathway are required for both E-cadherin and MT1MMP trafficking. This new localization of E-cadherin and its implication in cell invasion shines a new light on hybrid EMT features in tumoral invasion.

Cell invasion | Hybrid cells | Matrix degradation | Pancreatic cancer | Recycling

Correspondence: frederic.andre@univ-amu.fr ; veronique.rigot@univ-amu.fr

\section{Introduction}

Cancer cells ability to invade the surrounding tissue and to metastasize to distant organs is a major contributor $(>90 \%)$ to cancer deaths $(1,2)$. Despite significant advances in cancer treatment, detection of an invasion-metastasis cascade at the earliest stage of the disease is crucial for the management and the prediction of cancer progression. The invasion-metastasis cascade consists of a series of inter-connected cell-biological events. Among those, alteration in cell-cell adhesion dynamics and local extracellular matrix (ECM) degradation constitute the first stage of this cascade1. In almost all carcinomas, aberrant activation of Epithelial-to-Mesenchymal Tran- sition (EMT) is essential for tumoral invasion and cancer cell metastasis (3). EMT has been defined as a multifaceted and often reversible conversion of cell phenotype. During this process, epithelial cells lose their apical-basal polarity, remodel their cytoskeleton and exhibit reduced cell-cell adhesive properties. These cells may individually or collectively acquire mesenchymal features and increase their motility and invasive ability(4). Traditionally, EMT has been described as a binary process requiring a full conversion from epithelial to mesenchymal state. However, recent in vitro and in vivo studies have revealed that cancer cells of various origin (breast, lung, prostate, pancreas, liver, colon,... ) may display a mixture of epithelial and mesenchymal traits at molecular and/or morphological levels (5-8). These observations highlight cancer cell ability to adopt hybrid Epithelial/Mesenchymal (E/M) phenotypes contributing to the intratumoral heterogeneity (7). It becomes clear that hybrid E/M phenotype can act as an indicator of poor prognosis : (1) cancer cells may metastasize with a partial loss of epithelial phenotype and/or a partial gain of mesenchymal traits (9), (2) a gene signature consisting of both Epithelial and Mesenchymal genes predicts a reduced survival of patients $(5,10)$. Classical cadherins represent a family of transmembrane glycoproteins that are primarily involved in calcium-dependent cell-cell adhesion, differentially expressed throughout the body (11). Cadherins establish adhesion between neighbouring cells through their extracellular domain and ensure the cohesion required for tissue integrity (12). The intracellular domain is associated with cytoplasmic proteins such as catenins which connect cadherins to the actin cytoskeleton and cell signalling pathways. For many years, complete downregulation of E-cadherin associated with an upregulation of $\mathrm{N}$-cadherin and/or P-cadherin during EMT process was considered as a crucial step in carcinoma progression to promote invasion and metastasis (13). Indeed, in vitro studies showed that E-cadherin positive cells exhibit epitheloid traits and non-invasive behaviour whereas fibroblastoid phenotype and invasive properties was observed for E-cadherin negative cells. According to this, E-cadherin down expression was observed in oesophageal, gastric, colon, and hepatocarcinoma. However, an inverse correlation between E-cadherin expression, cell invasion and metastasis is not absolute. A growing number of studies revealed that some tumour cells with epithelial traits and still expressing E-cadherin can undergo metastasis and form secondary tumours $(14,15)$. In some 
invasive and metastatic cancers including prostate, ovarian, breast and glioblastoma, high levels of E-cadherin expression was described (16-18). Moreover, E-cadherin was described as a promoter of metastasis in diverse models of invasive ductal breast carcinomas (19). These studies suggest that in some tumours, E-cadherin may promote metastasis instead of suppressing tumour progression. However, the molecular mechanisms involved in this process remain to be elucidated. Pancreatic ductal adenocarcinoma (PDAC) as a highly metastatic with poor prognosis cancer $(20,21)$ is an useful model to clarify the impact of E-cadherin on tumour progression. Indeed, it is now recognized that PDAC encompass a range of E/M hybrid cells, reflecting epithelial-mesenchymal plasticity $(8,22-24)$. Moreover, some PDAC cells with high Ecadherin expression at the cell boundaries exhibit highly invasive and malignant behaviour 15 . To address the role of Ecadherin in PDAC aggressiveness, we downregulated its expression in a pancreatic model of E/M hybrid cells and analysed the consequences of E-cadherin depletion on the cell capacity to form invadopodia. Furthermore, we deciphered the molecular mechanisms by which E-cadherin regulates invadopodia formation.

\section{Results}

For years now, E-cadherin is often considered as a tumour/invasion suppressor. However, recent studies demonstrated the involvement of E-cadherin in tumour invasion process 19,24,31. To clinically confirm E-cadherin's profile in pancreatic cancer, we first accessed $\mathrm{PaCaOmics}$ data constituted by a series of patient-derived xenografts (PDX) from a multi-centric clinical trial (25). PDAC tumours included in this $\mathrm{PaCaOmics}$ program are considered as localised, locally advanced and metastatic (25). From these PDX samples, RNA-seq analysis were performed and E-cadherin protein expression was determined by immunodetection and scored as described in material and methods. First, we tried to correlate E-cadherin expression at RNA or protein levels respectively with various criteria: (1) the survival rate of patients (Figure 1A and 1B); (2) the stages of the pathology (localised, locally advanced and metastatic) (Figure 1C and 1D); (3) the pancreatic adenocarcinoma molecular gradient (PAMG) ; a transcriptomic signature that predicts clinical outcome (25) (Figure 1E and 1F) and (4) the subtypes of PDAC-Classical vs Basal-like subtypes (26) (Figure 1G and 1H). While few differences were observed at RNA levels for both the stages of the pathology (Figure 1C) and the Classical vs Basal-like subtypes (Figure 1G), these observations were not extended to protein expression levels (Figure 1D and 1H). Therefore, E-cadherin expression is not associated with tumour stages, prognosis, and overall survival in PDAC. This suggests that E-cadherin should not be considered as a tumour/invasion suppressor in PDAC. According to this hypothesis, we next determined whether E-cadherin plays a role in PDAC invasion. We therefore focused our study on the involvement of E-cadherin in the formation of the invadopodia, an earliest stage of invasion process (27). The human pancreatic cancer cell line BxPC-3 was used as a model sys- tem since these cells express high levels of E-cadherin and form invadopodia (24) (Fig S1). XZ confocal projections showed localization of actin spots associated with several invadopodia markers (Cortactin, Tks5 and MT1-MMP) within a degradation area of the FITC-labelled Gelatin (Fig S1A, 1B and 1C). As shown in the literature, invadopodia activity requires both MMPs and MT1-MMP (28). Since MMPs inhibitor (GM6001) (Fig S1D) as well as MT1-MMP depletion by siRNA strategy (Fig S1E and 1F) reduced almost entirely the number of cells forming invadopodia $(0,24 \pm 0,05$ vs $0,022 \pm 0,01$ for GM6001 treatment and 0,63 $\pm 0,033$ vs $0,11 \pm 0,14$ for siRNA knockdown), these data confirm that BxPC-3 cells forms active invadopodia.

To study the role of E-cadherin in invadopodia formation and function, we generated stable BxPC-3 cell lines termed ShCTRL (no cadherin depletion) and BxPC-3 shEcad (Ecadherin depletion) (24). Invadopodia assays revealed a significant decrease in the number of cells forming invadopodia when E-cadherin is depleted $(65,1 \pm 7,1$ vs $22,9 \pm 2,2)$ (Figure 2A). Moreover, the areas of FITC-labelled gelatin degradation were reduced upon E-cadherin depletion $(9,25$ $\pm 1,5$ vs $0,47 \pm 0,27$ ) (Figure 2B). Further quantification in absence of E-cadherin highlight a significant decrease in the number of invasive structures per cell (Figure 2C). Actin and E-cadherin co-immunostaining indicated that a pool of E-cadherin is located at the invadopodial membrane (Figure 2D). We confirmed this observation by using several E-cadherin antibodies, raised either against the extracellular or the intracellular domain of E-cadherin (Figure 2D and Figure S2A). To confirm this localisation, BxPC-3 cells were plated on non-fluorescent gelatin for $16 \mathrm{~h}$ before invadopodia purification. Western blotting experiment revealed a pool of E-cadherin in the invadopodia fraction (Figure S3). E-cadherin was also detected in the invadopodia formed by the pancreatic cancer primary culture PDAC001T (Figure 2E). Moreover, the presence of E-cadherin in these structures could be extended to human PDX sample issued from breast cancer cell (SUM-149) (Figure 2F). Therefore, this unexpected E-cadherin localisation is not restricted to PDAC. These observations suggest a direct role of Ecadherin in invadopodia formation. To be functional, Ecadherin requires interactions with cytoplasmic molecules called catenins. Proximity ligation assays (PLA) indicated that E-cadherin associates with $\beta$-catenin within invadopodia structures (Figure 2G). Moreover, two synthetic Ecadherin inhibitors (AS9 and AS11) that block the transinteractions of E-cadherin molecules in junctional complex (29), reduced the number of cell exhibiting invadopodia (Figure $2 \mathrm{H}$ ). These data strongly confirm the presence of pool of functional E-cadherin at the invadopodial membrane. As BxPC-3 cells express both E-cadherin and P-cadherin, we were able to show by confocal microscopy that P-cadherin is not detected in invadopodia (Figure S2B). This indicates that E-cadherin localisation at invadopodial membrane could not be extended to other cadherins. We next determined whether E-cadherin is localized in invadopodia

in vivo. We immunostained 2 invadopodia markers (Cortactin 
A

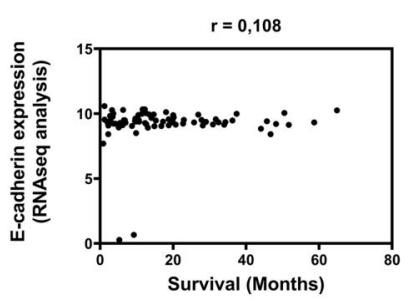

C

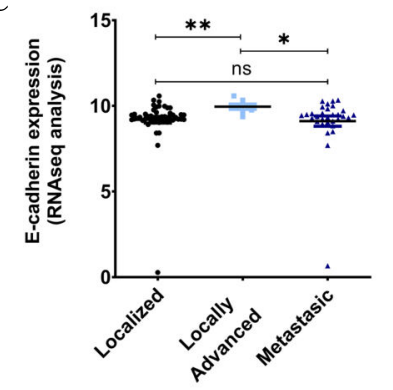

$\mathbf{E}$

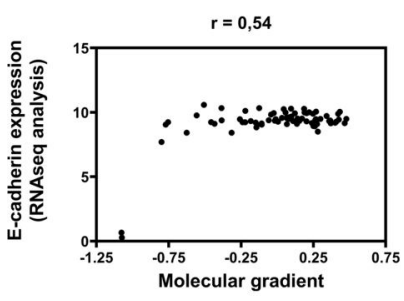

G

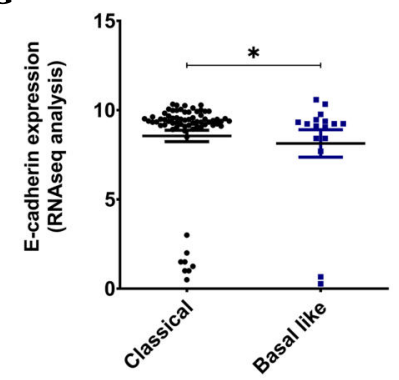

B

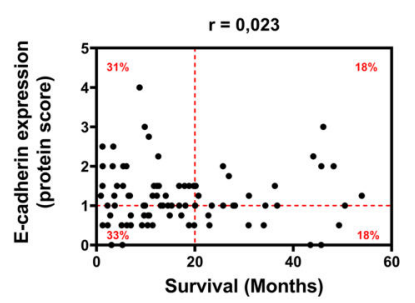

D

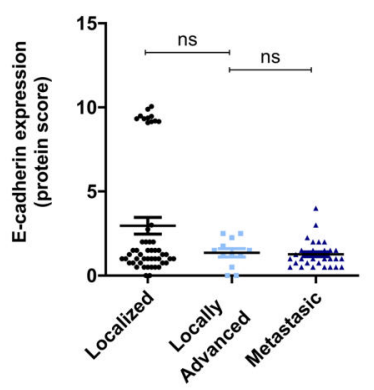

F

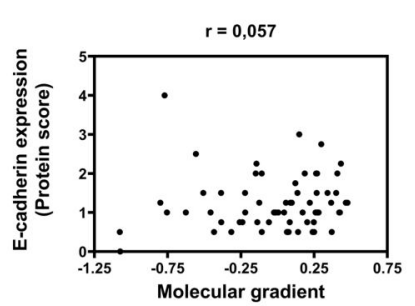

$\mathbf{H}$

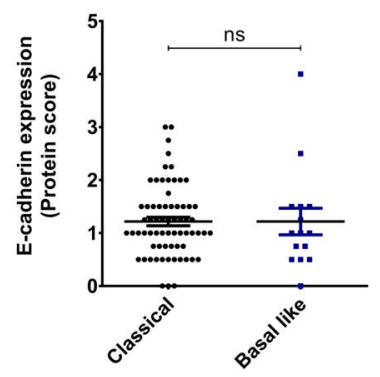

Fig. 1. E-cadherin expression is not a protective marker for PDAC aggressiveness. (A) Correlation between mRNA expression and patients' survival.mRNA expression was obtained by RNAseq performed on 90 patient tumours included in $\mathrm{PaCaOmics}$ program. (B) E-cadherin protein score from $\mathrm{PaCaOmics}$ xenograft tumours. E-cadherin was immunodetected on a tissue array containing PDAC samples from xenograft tumour. E-cadherin staining was scored as described in Materials and Methods. (C) Averaged E-cadherin mRNA expression following the clinical stages of the tumour: Localized $(n=50)$; Locally advanced $(n=7)$; Metastatic $(n=31)$. mRNA expression was obtained by RNAseq performed on 90 patient tumours included in $\mathrm{PaCaOmics}$ program. ns $=$ non-significant. (D) E-cadherin expression in relation with the clinical localisation of the tumour. E-cadherin was immunodetected on a tissue array containing PDAC samples from 83 xenograft tumours. Tumours were classified as Localized $(n=50)$; Locally advanced $(n=12)$; Metastatic $(n=31)$. ns= nonsignificant. (E) Correlation between E-cadherin mRNA expression and molecular gradient signature. mRNA expression was obtained by RNAseq performed on 90 patient tumours included in $\mathrm{PaCaOmics}$ program. (F) Correlation between E-cadherin protein expression and molecular gradient signature $(n=83)$. (G) Averaged E-cadherin mRNA expression for classical and basal-like subtypes in PDX: Classical $(n=68)$; Basal-like $(n=16)$. mRNA expression was obtained by RNAseq performed on 90 patient tumours included in $\mathrm{PaCaOmics}$ program. (H) E-cadherin expression in relation with clinical stages of the pathology of the tumour. E-cadherin was immunodetected on a tissue array containing PDAC samples from 83 xenograft tumours. Tumours were classified as Localized $(n=50)$; Locally advanced $(n=12)$; Metastatic $(n=31)$. ns= nonsignificant. and Tks5) and E-cadherin in BxPC-3 cells ectopically implanted in mice. On serial tissue sections, colocalization of Cortactin/E-cadherin (Figure 3A; White arrows) and Cortactin/Tks5 (Figure 3B; White arrows) were observed at same sites and localized in close contact with the microenvironment. To confirm this observation, we performed a Cortactin/Tks5/E-cadherin triple staining on tissue sections issued from human PDAC (Figure 3C; White arrows) and found that a pool of E-cadherin localized with Cortactin and Tks5 at the invasive front of the tumour. MT1-MMP, a transmembrane protease, is stabilized at invadopodial membrane by a direct interaction with F-actin, providing a link between the F-actin core of invadopodia and the invadopodial membrane (30). Since E-cadherin also indirectly interacts with Factin at the invadopodial membrane, we determined whether E-cadherin could interact with MT1-MMP. Immunoprecipitations experiments performed on BxPC-3 cell lysates revealed that a fraction of E-cadherin precipitates with MT1MMP suggesting that both molecules form a complex (Fig- ure 4A). PLA confirmed that E-cadherin interacts with MT1MMP within invadopodia structures (Figure 4B). A decrease in the invadopodia number could be detected in cells that exhibit intercellular contacts (Figure 4C). This observation indicates a link between cell interactions and invadopodia formation and suggests that the endocytic/exocytic fluxes of cell-cell contacts components are crucial for invadopodia activity. According to this, endocytosis inhibition by Dynasore promotes a significant reduction of BxPC-3 cells forming invadopodia $(0,46 \pm 0,01$ vs $0,23 \pm 0,01)$ (Figure 5A). Ecadherin is continuously turned over and undergoes cycles of endocytosis, sorting and recycling to the plasma membrane (31). E-cadherin recycling requires Rab positive compartments including both Rab7 and Rab11 vesicles $(31,32)$. We therefore assessed whether these compartments regulate invadopodia formation. Rab7 $(1,8 \pm 0,3$ vs $1,01 \pm 0,04)$ or $\operatorname{Rab11}(1,67 \pm 0,45$ vs $1,351 \pm 0,48)$ depletion by siRNA strategy induced a significant decrease in the number of invadopodia formed per cell (Figure 5B and 5C; left panel, 
bioRxiv preprint doi: https://doi.org/10.1101/2020.10.09.332783; this version posted October 9, 2020. The copyright holder for this preprint (which was not certified by peer review) is the author/funder, who has granted bioRxiv a license to display the preprint in perpetuity. It is made available under aCC-BY-NC-ND 4.0 International license.

A

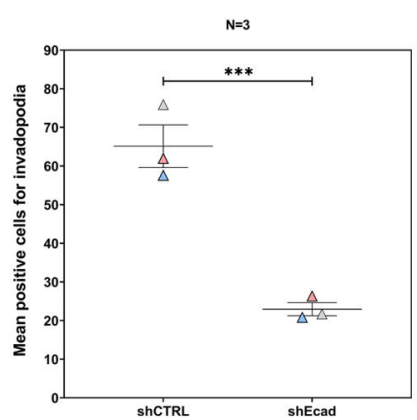

C

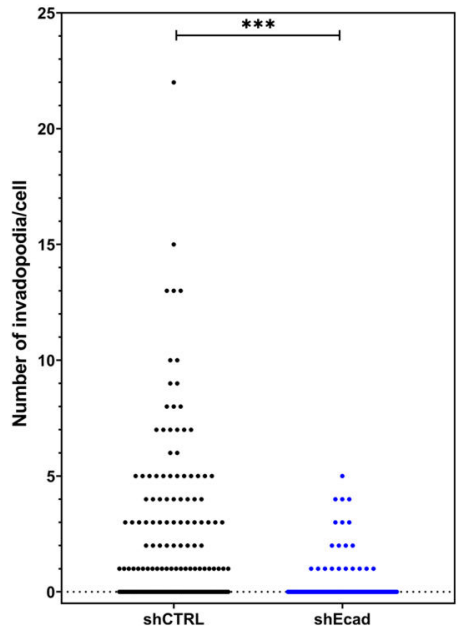

B

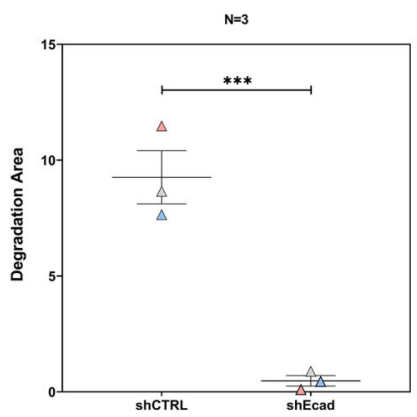

$\mathbf{E}$

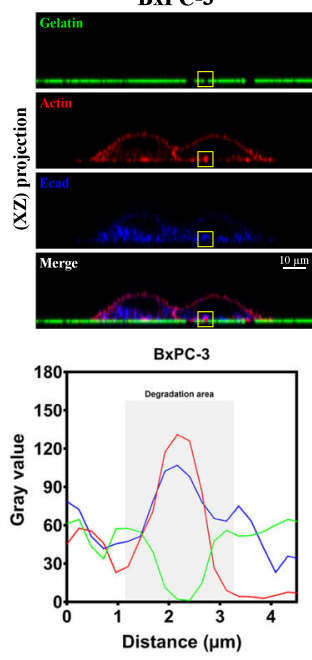

D $\quad$ BxPC-3

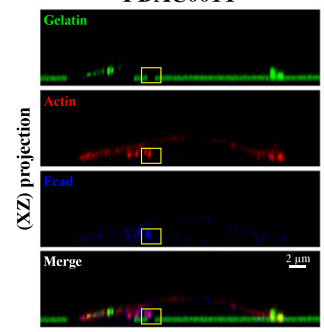

PDAC001T

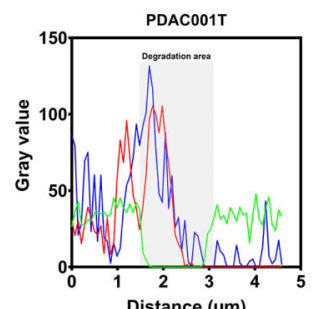

$\mathbf{F}$

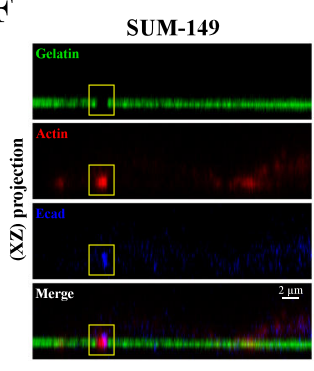

SUM-149

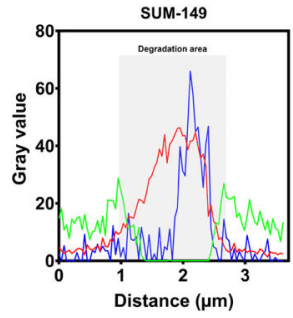

G
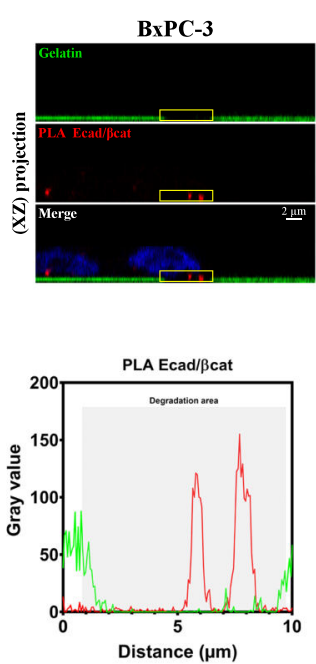

$\mathbf{H}$

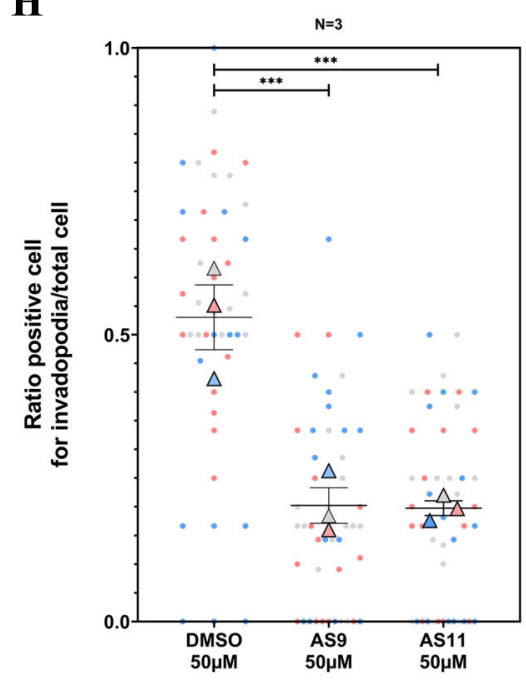

Fig. 2. E-cadherin is involved in invadopodia formation.Invadopodia assay were performed as described in material and methods. Co-localization of an actin spot with a degradation zone of the gelatin (black area) represents an active invadopodia.(A) Quantification of positive cells for active invadopodia in BxPC-3 shCTRL and shEcad cell lines. Means from 3 independent experiments are indicated with coloured triangle. Errors bars represent Mean \pm SEM.(B) Quantification of normalized gelatin degradation area under BxPC-3 shCTRL and shEcad cells. Means from 3 independent experiments are indicated with coloured triangle. Errors bars represent Mean \pm SEM.(C) Graphical distribution of the number of invadopodia formed by BxPC-3 shCTRL and shEcad cells. Raw data from a representative experiment are shown on the graphic.(D-F) Pancreatic cancer BxPC-3 cell line (D), pancreatic cancer primary culture PDAC001T (E) and breast cancer cells SUM-149 cell line (F) were cultured on fluorescent gelatin. Left panel: cells were stained for actin (red), E-cadherin with an antibody directed to the cytoplasmic domain (blue) and gelatin (green). Images represent Z-stack confocal acquisitions. Scale bar $=2 \mu \mathrm{m}$. Right panel: fluorescence intensity quantification of the ROI indicated by the yellow square on the left panel.(G) E-cadherin and $\beta$-catenin interacts in invadopodia. E-cadherin/ $\beta$-catenin complexes were detected using Proximity Ligation Assay (PLA). Z-stack confocal acquisitions were performed. Left panel: the amplification spot (in red) localizes in a degradation spot of the fluorescent gelatin (in green). Right panel: fluorescence intensity quantification of the ROI indicated by the yellow square on the left panel. Scale bar represents $2 \mu \mathrm{m} .(\mathbf{H})$ Ratio of positive cells for active invadopodia in treated (AS9 AS11; chemical E-cadherin inhibitors) and untreated (DMSO) BxPC-3 cells. Mean from 3 independent experiments are indicated with coloured triangle. Raw data are shown with coloured dots. Errors bars represent Mean \pm SEM. 
bioRxiv preprint doi: https://doi.org/10.1101/2020.10.09.332783; this version posted October 9, 2020. The copyright holder for this preprint (which was not certified by peer review) is the author/funder, who has granted bioRxiv a license to display the preprint in perpetuity. It is made available under aCC-BY-NC-ND 4.0 International license.
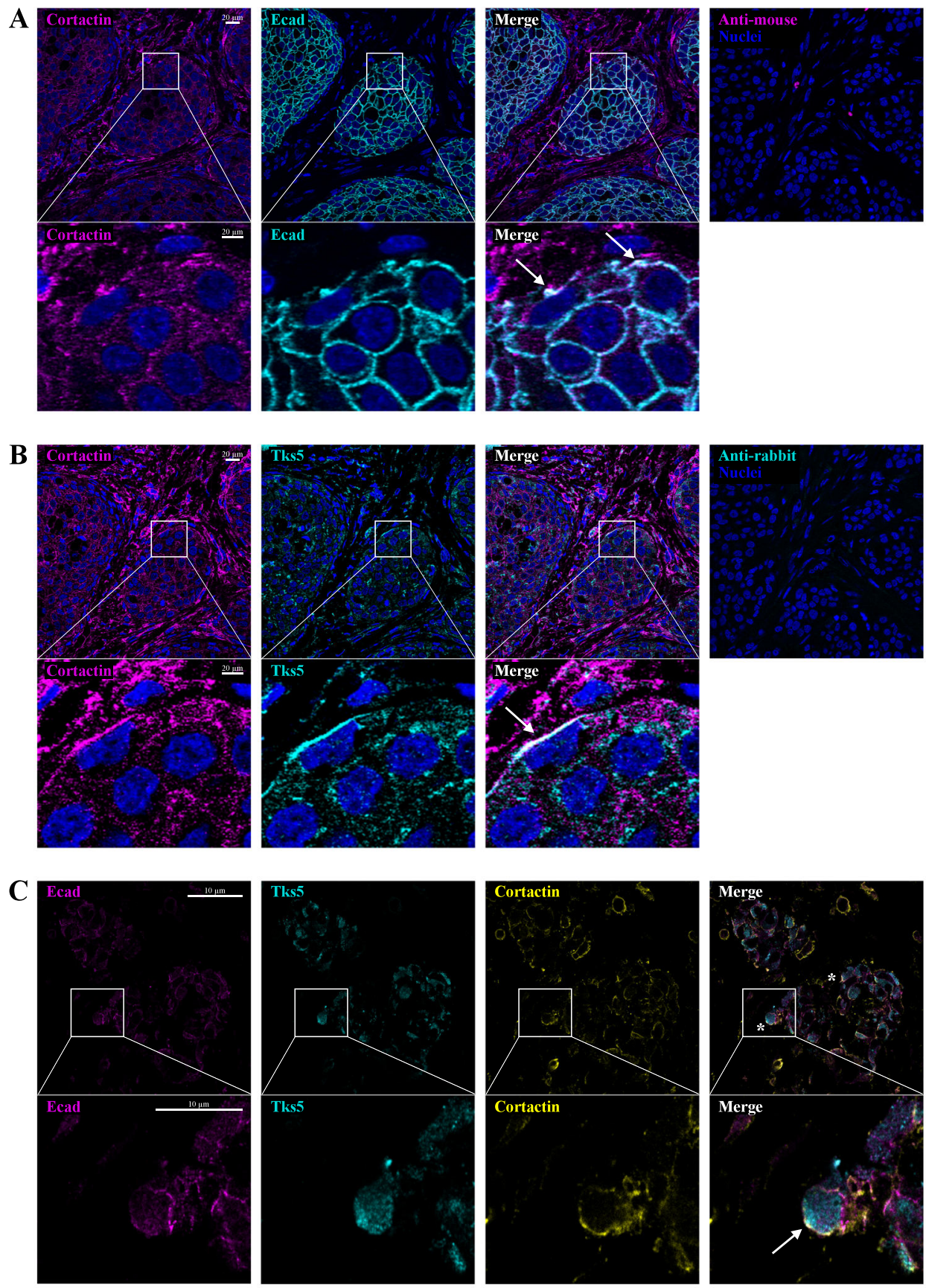

Fig. 3. E-cadherin localization in invadopodia-like structures ex-vivo and in-vivo.(A-B) Colocalization of E-cadherin, Tks5, and cortactin in serial sections from subcutaneous tumours of BxPC3 cells by double staining: (A) Cortactin and E-cadherin or (B) Cortactin and Tks5 and nuclei staining with Dapi. Scale bars represent 10 $\mu$ m. White

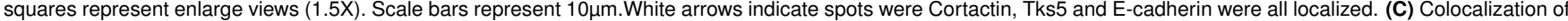
E-cadherin, Tks5, and cortactin in patient tumours section. White squared represent enlarge views (1.5X). White arrows indicate invadopodia containing E-Cadherin. Scale bars represent $10 \mu \mathrm{m}$. 
Figure S4A and 4B). Most importantly, depletion of both $\operatorname{Rab} 7(0,24 \pm 0,06$ vs $0,15 \pm 0,07)$ and $\operatorname{Rab} 11(0,25 \pm 0,07$ vs $0,09 \pm 0,04$ ) leads to a significant decrease in the number of invadopodia containing E-cadherin (Figure 5B and 5C; right panel) strongly suggesting that E-cadherin recycling to invadopodial membrane requires both Rab7 and Rab11 dependent pathways. To confirm this hypothesis, we managed to detect E-cadherin in Rab7 and Rab11 vesicles (Figure 5D and 5E). We observed E-cadherin/Rab7 and E-cadherin/Rab11 complexes in the immediate vicinity of degradation areas. MT1-MMP was also detected in these compartments (Figure $\mathbf{5 F}$ and 5G). These data indicate that E-cadherin is recycled simultaneously with MT1-MMP through Rab7 and Rab11 pathways. Altogether, these data suggest that MT1-MMP and E-cadherin could interact with each-other during their traffic to invadopodial membrane.

We sought to determine by which mechanism E-cadherin expression could regulate the formation of invadopodia. IPA comparative analysis of proteomes from shCTRL and shEcad cell generated by mass spectrometry analysis of cell lysate, showed at least 8 signalling pathways deregulated which could be crucial for invadopodia formation when E-cadherin is depleted. Among those signalling pathways, we found both caveolar and clathrin-mediated endocytosis, integrin, actin cytoskeleton, remodelling of epithelial adherens junctions, actin nucleation through Arp/WASP complex, Cdc42 signalling and $\mathrm{Wnt} / \beta$-catenin pathway (Figure 6A). We focused on the actin nucleation by Arp $2 / 3$ complex since this pathway has been described in both E-cadherin traffic and invadopodia formation37,39. E-cadherin depletion induced a downregulation of the 8 subunits (ACTR2, ACTR3, ARPC2, ARPC3, ARPC4, ARPC5L, ARPC1A and ARPC1B) of the Arp $2 / 3$ complex (Figure 6B). In addition, interactome analysis identified Arp2/3 complex as a partner of both E-cadherin and $\beta$-catenin interaction networks (Figure 6C). Arp $2 / 3$ complex is essential for actin branched structures found in invadopodia. Thereby, we focused our attention on Arp3 encoded by ACTR3 gene. Arp3 subunit down-expression in E-cadherin depleted cells was confirmed by Western Blot analysis (Figure 6D). A pool of Arp3 associates with both cortactin and E-cadherin close to gelatin degradation areas suggesting its implication in invadopodia organisation Figure $6 \mathrm{E}$ and $6 \mathrm{~F}$ ). Arp3 subunit depletion confirms this hypothesis since siRNAs against Arp3 promoted a significant decrease in the number of invadopodia formed per cell $(1,77$ $\pm 0,27$ vs $0,99 \pm 0,26$ ) (Figure 6G and 6H). Altogether, these data highlight the importance of the E-cadherin into the actin nucleation through ARP/WASP complex. In the absence of the E-cadherin, Arp3 is down-regulated and the actin nucleation does not take place preventing the formation of the actin protrusion.

\section{Discussion}

During these last few years, many researches revealed that tumour cells with epithelial traits and expressing high level of E-cadherin can undergo metastasis and form secondary tumours $(8,15,22)$. This would suggest that E-cadherin is not always a protective factor and may play, in some cases, an important role in cancer cell invasion and dissemination. To address E-cadherin role in PDAC aggressiveness, we have down-regulated E-cadherin expression in a pancreatic model of E/M hybrid cells and analyzed the consequences on cell invasion. According to our data, the contribution of E-cadherin on pancreatic cancer invasion can be summarized as follows: (i) E-cadherin expression is not associated with stages of the pathology, prognosis, and overall survival in PDAC; (ii) Ecadherin is a prominent component of invadopodia in PDAC. E-cadherin knockdown or inhibition abrogated invadopodia formation; (iii) E-cadherin expression level regulates actin nucleation involved in invadopodia formation by modulating the expression of Arp $2 / 3$ complex components; and (iv) Ecadherin is recycled at the invadopodial membrane simultaneously with MT1-MMP through Rab7 and Rab11 pathways. In cancer, EMT is associated with tumour initiation, invasion, metastasis, and therapy resistance (7). Recent reports pointed out EMT as a non-binary process. The conversion from epithelial to mesenchymal state in not total as a range of hybrid $\mathrm{E} / \mathrm{M}$ states have been identified $(5,33)$. These $\mathrm{E} / \mathrm{M}$ hybrid cells possess a higher metastatic risk and a gene signature composed by both24 epithelial and mesenchymal genes leading to a poor outcome $(5,9,33)$. PDAC exhibit E/M hybrid cells $(8,22,24,34)$ that may contribute to the well-known heterogeneity in this kind of tumour. The role of E/M hybrid cells on PDAC aggressiveness remains largely unknown but they should impact cancer cell invasion and dissemination (8). Indeed, hybrid E/M phenotype facilitates collective cell migration, circulating tumour cell clusters formation and metastatic outgrowth, by maintaining cell-cell contact between tumour cells. This suggest that hybrid E/M cells are associated with increased metastatic potential. In this study, by using a human pancreatic cell line BxPC-3 cell line coexpressing epithelial and mesenchymal markers $(8,24)$, we confirmed that hybrid E/M phenotype should be associated to PDAC aggressiveness. Indeed, we report that E-cadherin knockdown, a hallmark of epithelial status, significantly reduces gelatinolytic activity of cancer cells. Moreover, both using in vivo cancer cell implantation models and human pancreatic cancer tissues, we observed tumour cells with retention of epithelial traits at the invasive front of PDAC. Literatures from two decades ago have developed the notion that E-cadherin acts as an invasion suppressor. Indeed, various reports have associated loss of E-cadherin expression with invasive and dedifferentiated or poorly differentiated carcinomas. General assumption that an inverse correlation between E-cadherin expression and invasive potential of carcinoma cells is not absolute. High level of E-cadherin expression was demonstrated in various invasive and metastatic cancer, including PDAC and breast cancer, suggesting that E-cadherin may have inefficient suppressive activity or, even worse, could promote metastasis instead of suppressing tumour progression $(15,33)$. Consequently, E-cadherin status appears to be important for tumorigenesis. According to this, a functional role of E-cadherin in promoting metastasis of breast cancer has been shown through a pro-survival 

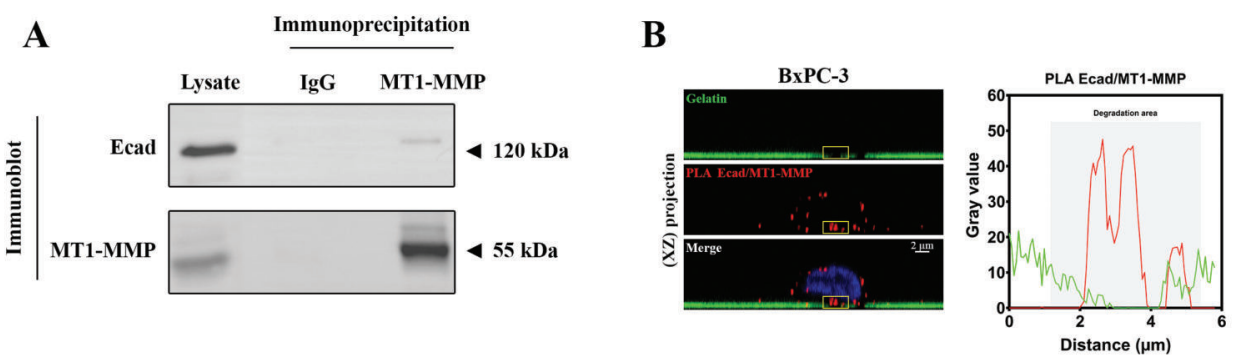

Fig. 4. E-cadherin physically interacts with MT1-MMP.(A) Equal amount of BxPC-3 cell lysates were immunoprecipitated using either anti-MT1-MMP or nonspecific (IgG) antibodies. After SDS-PAGE and transfer onto PVDF membrane, protein complexes were detected using $\mathrm{E}$ cadherin or MT1-MMP antibodies. In control western blot performed on BxPC3 lysates (B) E-cadherin and MT1-MMP colocalize inside invadopodia structure. After E-cadherin and MT1-MMP immunostaining, E-cadherin/MT1-MMP complexes were detected using PLA. Z-stack confocal acquisitions were performed. Left panel: The amplification spot (in red) localizes in a gelatin degradation area. Scale bar = $2 \mu \mathrm{m}$. Right panel: Fluorescence intensity quantification of the ROI indicated by the yellow square on the left panel. (C) Cell-cell interactions inhibited invadopodia formation. After cell fixation the number of invadopodia per cell was measured as described in Material and Methods section. The graph represents the distribution of invadopodia in isolated cells ( 1 cell), cell doublet (2 cells) or groups superior of 2 cells ( $>2$ cells). Raw data are shown with coloured dots. Mean from 2 independent experiments are indicated with coloured triangle. Errors bars represent Mean \pm SEM.

signalling axis (19). Moreover, E/M hybrid cells expressing E-cadherin might confer collective migratory ability to tumour cells while allowing them to survive during transit and colonization in distant organs $(8,35,36)$. Yet, the prometastatic function of E-cadherin is likely to be context dependent. Our results reveal that in PDAC, E-cadherin expression is not associated with stages of the pathology, poor prognosis, and poor overall survival in PDAC. However, complementary with our previous data, we showed that E-cadherin participates to cancer cell invasion by regulating invadopodia formation (24). Invadopodia are actin-rich plasma membrane protrusions developed by cancer cells and are implicated in the basement membrane and interstitial matrix remodelling and degradation (37). Key components of invadopodia include the scaffold protein Tks5, the actin regulators cortactin, Wiskott-Aldrich syndrome protein family members, cofilin, and MT1-MMP (38). Invadopodia are hallmarks of invasive cells. Indeed, they are mainly identified in invasive cancer cell lines including breast, head and neck, prostate, fibrosarcoma and melanoma(39). If invadopodia have been extensively studied in cell culture, they have now been detected using in situ tissue explants, tissues sections and in vivo models (40). By immunostaining Tks5 on PDAC surgical specimens, Chen et al. observed Tks5-positive puncta associated with tumour cells and suggested the presence of invadopodia-like structures inside human tumours (41). Our data strengthen the physiological relevance of invadopodia in
PDAC. Indeed, by using cancer cell implantation models in vivo and human pancreatic cancer tissues we showed that the 2 most commonly used invadopodia markers (cortactin and Tks5) colocalize at tumour cell membrane sites preferentially localized at the tumour invasive front. Increasing evidence show that invadopodia are required for cancer cell invasion and metastasis(42) providing a strong rationale for therapeutically inhibiting invadopodia to prevent metastasis. However, the ability of pancreatic cancer cells to form invadopodia has not yet been correlated with PDAC aggressiveness. Further studies based on the use of large PDAC patient cohorts are required to demonstrate a link between invadopodia assembly and pancreatic cancer cell invasion/metastasis. We provide multiple lines of evidence that E-cadherin is a key component of the invadopodial membrane. (1) E-cadherin localizes with both cortactin and Tks5 at the tumour invasive front ; (2) a pool of E-cadherin is detected at the invadopodial membrane in pancreatic BxPC-3 cell line, pancreatic cancer primary culture and a PDX sample issued from breast cancer cell. Moreover, E-cadherin interacts with the main components of invadopodia including cortactin, Tks5 and MT1-MMP; (3) E-cadherin is found in purified invadopodia; (4) E-cadherin but not P-cadherin knockdown or inactivation impairs invadopodia formation. Knowing the critical role of invadopodia in cancer cell invasion, this unforeseen role might explain the detection of E-cadherin in invasive PDAC. It should be noticed that the zonula occludens protein $\mathrm{ZO}-1$ 
bioRxiv preprint doi: https://doi.org/10.1101/2020.10.09.332783; this version posted October 9, 2020. The copyright holder for this preprint (which was not certified by peer review) is the author/funder, who has granted bioRxiv a license to display the preprint in perpetuity. It is made available under aCC-BY-NC-ND 4.0 International license.

A

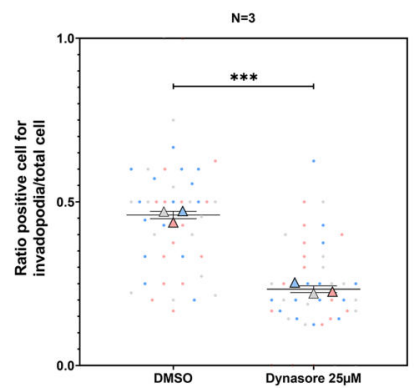

B

C
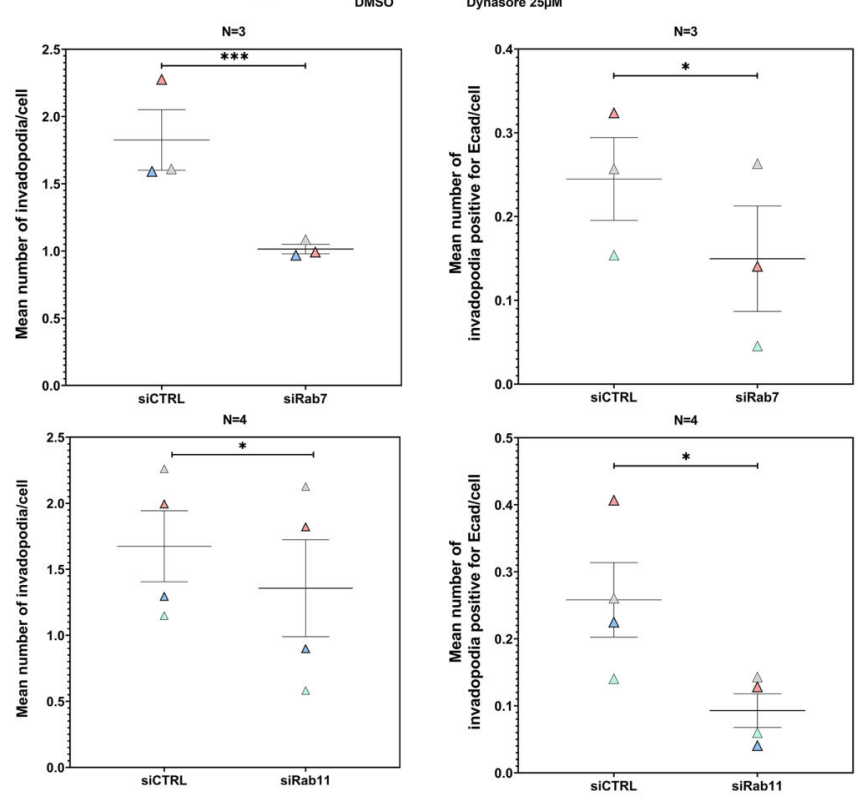

D

BxPC-3
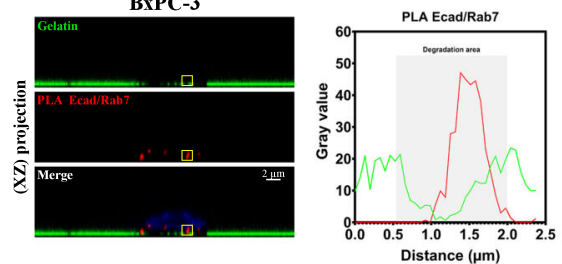

$\mathbf{E}$
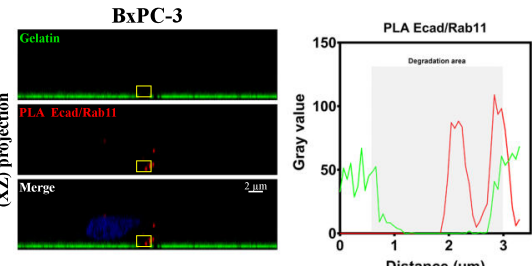

F

BxPC-3
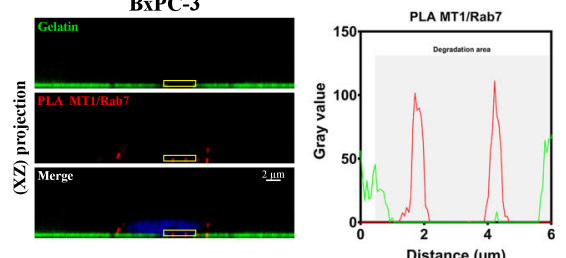

G
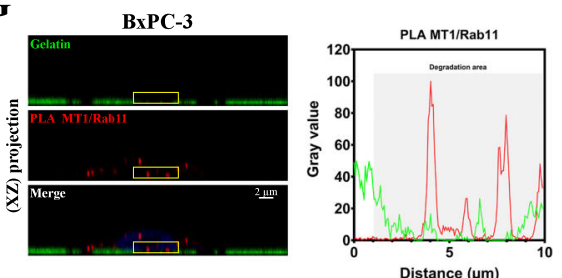

Fig. 5. E-cadherin recycling through Rab7 and Rab11 pathways induces invadopodia formation.(A) Invadopodia formation is dependant of endocytosis pathway: BxPC-3 cells were incubated with DMSO or with $25 \mu \mathrm{M}$ Dynasore (endocytosis inhibitor). The ratio of positive cells for active invadopodia was measured. Mean from 3 independent experiments are indicated with coloured triangle. Raw data are shown with coloured dots. Errors bars represent Mean \pm SEM. (B) BxPC-3 cells were treated for $48 \mathrm{~h}$ with siRNA control (siCTRL) or siRNA against Rab7 vesicles (siRab7) before invadopodia assay. Left panel: Quantification of the number of active invadopodia under BXPC-3 shCTRL cells. Right panel: Quantification of the number of active invadopodia positives for E-cadherin. Data correspond to a mean from 3 independent experiments indicated with coloured triangle. Errors bars represent Mean \pm SEM.(C) BxPC-3 cells were treated for 48h with siRNA control (siCTRL) or siRNA against Rab11 vesicles (siRab11) before invadopodia assay. Left panel: Quantification of the number of active invadopodia formed under BxPC-3 shCTRL cells. Right panel: Quantification of the number of active invadopodia positive for E-cadherin. Data correspond to a mean from 4 independent experiments indicated with coloured triangle. Errors bars represent Mean \pm SEM.(D-G) Protein-protein interactions in invadopodia revealed by Proximity ligation assay (D) E-cadherin and Rab7; (E) E-cadherin and Rab11; (F) MT1-MMP and Rab7; (G) MT1-MMP and Rab11. Z-stack confocal acquisitions were performed on the fixed cells. Left panel: The amplification spot (in red) co-localize with a degradation spot of the fluorescent gelatin (in green). Right panel: Fluorescence intensity quantification of the ROI indicated by the yellow square on the left panel. Scale bar represents $2 \mu \mathrm{m}$. 
bioRxiv preprint doi: https://doi.org/10.1101/2020.10.09.332783; this version posted October 9, 2020. The copyright holder for this preprint (which was not certified by peer review) is the author/funder, who has granted bioRxiv a license to display the preprint in perpetuity. It is made available under aCC-BY-NC-ND 4.0 International license.

A

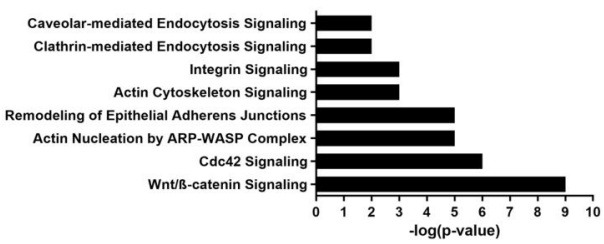

C

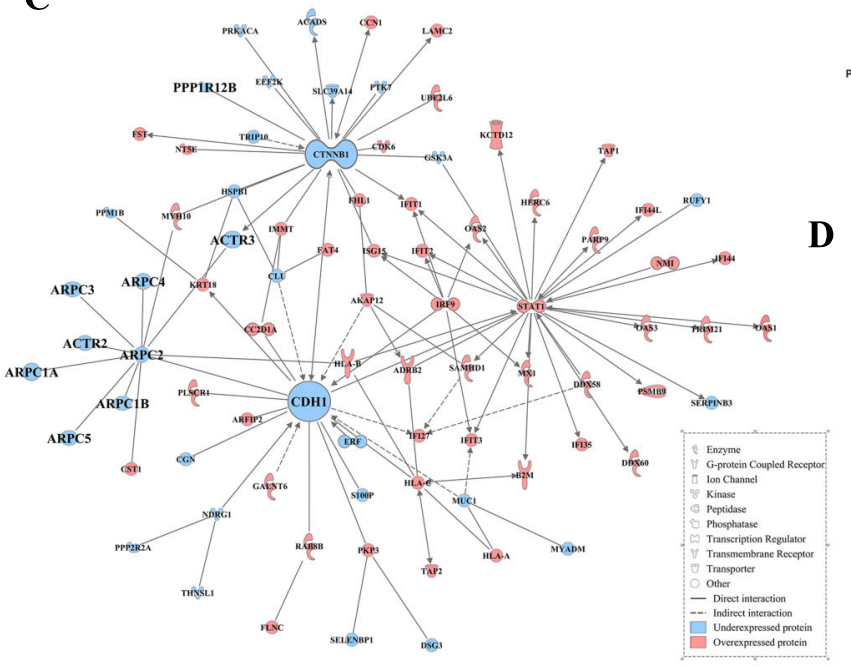

B

D
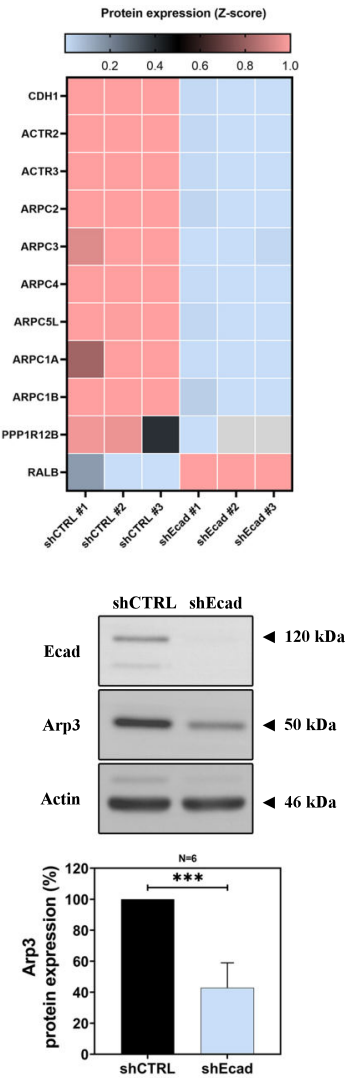

$\mathbf{F}$
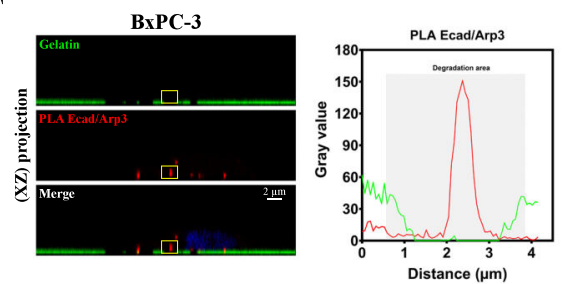

$\mathbf{H}$
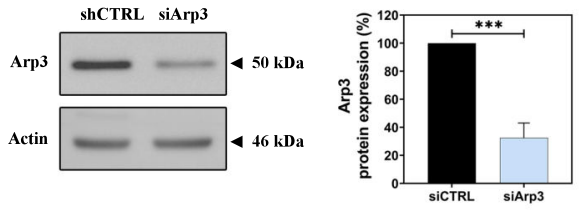

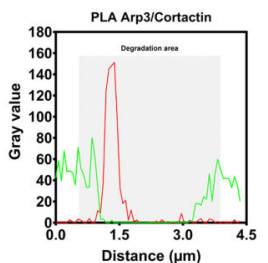

$N=3$

G

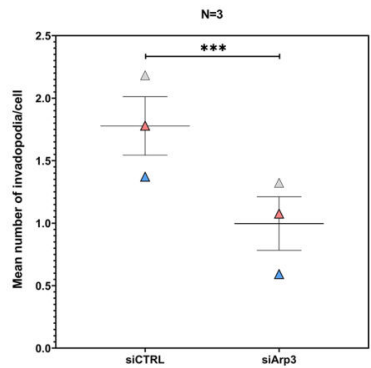


localizes at the invadopodial membrane of breast cancer cells, indicating that various cell-cell adhesion components should regulate invadopodia formation (43). E-cadherin is continuously turned over and undergoes cycles of endocytosis, sorting and recycling to the plasma membrane (31). Once internalized, E-cadherin enters in a Rab5 dependent compartment, which is central for sorting of most cell surface receptors. E-cadherin is then either sorted back to plasma membrane through recycling endosome or it is sequestered into vesicles positive for Rab7. E-cadherin trafficking to the plasma membrane requires either a rapid Rab4 dependent route or a slow Rab11 recycling pathway (31). In this study, we answer important outstanding questions regarding E-cadherin delivery to invadopodial membrane. When cell-cell contacts are reduced in E/M hybrid cells, E-cadherin acquires new localization and function related to the invasive properties of pancreatic cancer cells. E-cadherin delivery to the invadopodial membrane requires its endocytosis and recycling through Rab positive compartments including both Rab11 and Rab7. This suggest that two independent recycling pathways participate to E-cadherin delivery to invadopodial membrane. MT1-MMP must be internalized and stored in intracellular compartments to be efficiently recycled to invadopodia51. Some members of the Rab family, including Rab5 and Rab7 are involved in the regulation of MT1-MMP recycling pathways (44). Here we postulate that, by interacting with Ecadherin, MT1-MMP also pass a Rab11 dependent recycling route. Arp2/3 complex is an heptameric protein complex that polymerizes actin filaments as branches from existing filaments generating a highly branched actin filaments network. Arp2/3 complex powers various cell processes including cell motility, endocytosis, vesicle trafficking and adherens junction stability $(45,46)$. Its impact on actin polymerisation is critical for invadopodia-based invasion program by driving invasive cell protrusions through the matrix and maintaining tight apposition of surface-exposed MT1-MMP with ECM (47). In cancer, the mechanistic adaptability of the actin network is regulated by both the cell microenvironment and the genetic heterogeneity of tumour cells55. In this study, we demonstrate a link between E-cadherin and Arp $2 / 3$ complex (1) IPA identified Arp $2 / 3$ as a direct partner of the E-cadherin interaction network. This observation is in agreement with studies that implicated Arp2/3 complex as a key actin assembly factor at E-cadherin mediated cell-cell contacts56; (2) E-cadherin associates with Arp3 in invadopodia ; (3) Ecadherin depletion induces a downregulation of the 8 subunits of the Arp2/3 complex. Therefore, impaired actin nucleation, due to E-cadherin depletion, prevents the formation of the actin protrusion which normally sustains invadopodia. Further studies are required to determine the relationship between the expression levels of both E-cadherin and Arp2/3 complex. We can hypothesise that the gene repressing transcription factors involved in EMT, including Snaill, Snail2, Zeb1, Zeb2 and Twist1, regulate Arp2/3 (48). On the other hand, we cannot exclude that Arp2/3 complex downexpression induced by E-cadherin depletion is not combined with endocytosis and vesicle trafficking default of the in-

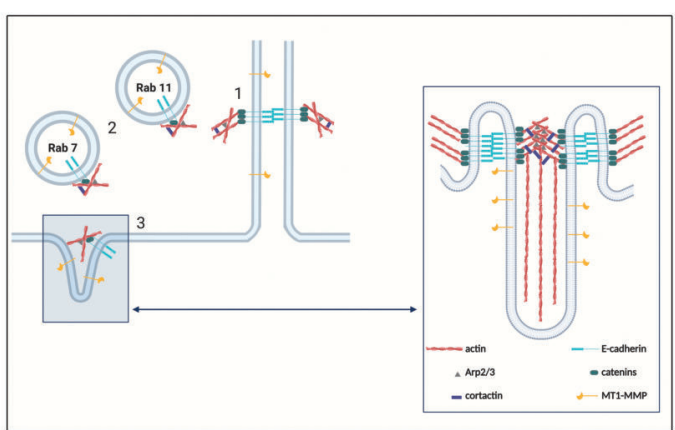

Fig. 7. Model.E-cadherin, initially localized in the adherens junctions could be recycled to the invadopodia structure simultaneously with MT1-MMP, through two different pathways: a Rab7 vesicle-dependant and/or a Rab11 vesicle-dependant pathway. Once translocated into the protrusion, E-cadherin will then interact with several invadopodia components such as Arp2/3, cortactin or MT1-MMP, and allows the actin nucleation resulting in the actin protrusion growth. As E-cadherin transinteractions are involved in invadopodia formation (cf. AS9 and AS11 inhibitors) and as $\mathrm{E}$-cadherin and $\beta$-catenin complex was also found in the protrusion, we can hypothesize a recycling of the adherens junction complex to stabilize the formation of the actin protrusion in invadopodia.

vadopodia components.

Altogether these data let us propose the following model to explain the pro-invasive effect of E-cadherin (Figure 7). Originally localized in the adherens junctions, E-cadherin could be endocytosed and recycled back to the invadopodial membrane simultaneously with MT1-MMP. Both Rab7 vesicle-dependant and/or a Rab11 vesicle-dependant pathway are required for E-cadherin trafficking. Once translocated into the immature invadopodia, E-cadherin will interact with several components such as Arp2/3, Cortactin and MT1-MMP. E-cadherin will then allow actin nucleation either indirectly by regulating Arp2/3 expression or directly by modulating the actin protrusion growth in the invadopodia.

\section{Materials and Methods}

E-cadherin RNA-seq and protein analysis on tumours samples. Data from $\mathrm{PaCaOmics}$ program (ClinicalTrials.gov: NCT01692873) were used for E-cadherin expression analysis. RNAseq was performed as previously described on PDAC samples from 90 xenograft tumours (25). E-cadherin was also immunodetected on a tissue array containing PDAC samples from 83 xenograft tumours. E-cadherin staining was scored as previously described (24). Different correlations were performed: E-cadherin transcript and E-cadherin protein level were correlated with the patient's survival or with the pancreatic adenocarcinoma molecular gradient (PAMG) signature (25).

Cell culture. The human pancreatic adenocarcinoma BxPC-3 cells, authenticated using short tandem repeat (STR) profiling (ATCC), the pancreatic cancer primary culture PDAC001T and Human breast cancer cells (SUM-149) were cultured as previously published $(24,49,50)$. E-cadherin was stably knockdown in the BxPC-3 cell line using shRNA lentiviral transduction particles (Sigma) as previously described(24). E-cadherin extinction was checked every 3 weeks by Western Blot analysis. 
Antibodies and reagents. Working dilutions and information of commercial antibodies and chemical reagents used in this study are listed in Supplemental Table 1.

Reverse siRNA transfection. For protein knockdown, reverse transfections were performed in 6 well plates. Cells were seeded directly with the siRNA/Transfection mix: $3 \mu \mathrm{l}$ of LipoRNAiMax (Lifetechnologies), 500 $\mu \mathrm{L}$ of OptiMEM (Gibco, Lifetechnologies), 25 or 50nM of indicated siRNA and $2.5 \mathrm{ml}$ of RPMI $/ 10 \%$ FCS medium. siRNA used for these studies are listed in Supplemental Table 2. When required, transfected cells were detached and seeded on FITC-gelatin coverslips, 24 or $48 \mathrm{~h}$ after treatment.

Subcutaneous xenografts of pancreatic cancer cells All experimental procedures involving animals were performed in accordance with the French Guidelines and approved by the ethical committee of Marseille (agreement 50-31102012). BxPC-3 cells were harvested by mild trypsinisation, washed twice in PBS, and then suspended in Matrigel at 2x106 cells per $100 \mathrm{ml}$. To induce tumours, cell suspension was injected subcutaneously (s.c.) into the flank of 6-8-week-old female NMRI-Foxn1nu/Foxn1nu mice (Charles River Laboratories, L'Arbresle, France). Injected mice were sacrificed 3 weeks after inoculation. Tumours were removed and tissue specimens were fixed in $4 \%$ formalin then embedded in paraffin.

Immunohistofluorescence. Tissue specimens were cut into $3 \mu \mathrm{m}$ sections. After dewaxing and antigen retrieval at $\mathrm{pH} 9$, sections were incubated for double or triple staining with primary antibodies or IgG1 isotype controls for $2 \mathrm{~h}$ at room temperature. After washing, the sections were incubated with Alexa conjugated antibodies, washed and mounted in aqueous mounting medium. Images were captured with LSM 880 Zeiss confocal microscope equipped with ZEN Software. Human pancreatic cancer samples were obtained as previously described (51).

Indirect immunofluorescence microscopy. Cells were fixed in $4 \%$ formaldehyde for $30 \mathrm{~min}$ then permeabilized and blocked in PBS/BSA 4\%/Saponin $0.1 \%$ for $1 \mathrm{~h}$. Cells were successively incubated with indicated primary antibodies in PBS/BSA $1 \% /$ Saponin $0.1 \%$ for $2 \mathrm{~h}$ at RT and with Alexa-Fluor-594 and -647 conjugated secondary antibodies (PBS/BSA 1\%/Saponin $0.1 \%, 1 \mathrm{~h}$ at $\mathrm{RT}$ ) raised against mouse and rabbit Igs. Samples were then washed and mounted in ProLong Gold antifade reagent (Thermofisher). Images were acquired with Sp5 Leica or LSM 880 Zeiss confocal microscopes equipped respectively with LAS AF Lite or ZEN Software. Z-Stack acquisitions (Range: $0.5 \mu \mathrm{m}$ ) were performed using a $63 \mathrm{X}$ objective magnification and analysed through orthogonal projections using ImageJ software (rsb.info.nih.gov/ij/).

Invadopodia assay. Coverslips were coated with FITC- conjugated gelatin (Sigma), fixed with Glutaraldehyde $0,5 \%$ and incubated for $3 \mathrm{~min}$ at RT with Sodium Borohydride $(5 \mathrm{mg} / \mathrm{ml})$. After several washes, 10000 isolated cells were seeded on top of the coverslip. BxPC-3 cells were incubated $16 \mathrm{~h}$ at $37^{\circ} \mathrm{C}$, fixed in $4 \%$ formaldehyde and stained for proteins of interest as described previously. The areas of degraded matrix were observed using a LSM880 Zeiss confocal microscope (25X objective). 15 microscopic fields per coverslips were acquired with all fluorescent channels.

Immunoprecipitation. BxPC-3 cells were plated in 10 $\mathrm{cm} 2$ culture dishes. Subconfluent cells (70\% of confluence) were lysed in ice with Lysis buffer (50mM Hepes $\mathrm{pH} 7.5$; 150mM Nacl; 1mM EDTA; 1mM EGTA; Glycerol 10\%; Triton X-100 1\%; 25mM NaF; $10 \mu \mathrm{M} \mathrm{ZnCl2} \mathrm{+} \mathrm{proteases}$ cocktail inhibitors). Protein G Sepharose beads (Roche) were pre-incubated with $1 \mu \mathrm{g}$ of indicated primary antibody for $2 \mathrm{~h}$ at $4^{\circ} \mathrm{C}$. After several washes, equal amount of cell lysate is incubated with pre-incubated beads for $2 \mathrm{~h}$ at $4^{\circ} \mathrm{C}$. After three washes in PBS, immunoprecipitated proteins were solubilized in Laemmli buffer, heated at $100^{\circ} \mathrm{C}$ for 5 min, and analysed by Western Blotting.

Western Blotting. Cells were lysed with $150 \mathrm{mM}$ RIPA Buffer (25mM Tris-HCl pH8.0; $150 \mathrm{mM} \mathrm{NaCl} ; 1 \%$ TritonX100) containing protease inhibitors cocktail. Equal amount of cell lysates $(25 \mu \mathrm{g})$ was resolved by SDS PAGE ( 8 or $10 \%$ polyacrylamide) and blotted onto a PVDF membrane. Proteins were detected with indicated antibodies (see Supplemental Table 1). Antigen/antibody complex was revealed using ECL detection system (Millipore) and visualized using a Pxi imaging device (SynGene).

Invadopodia purification. Invadopodia enrichment was performed as previously described (52). 250000 cells were seeded in $10-\mathrm{cm} 2$ dishes pre-coated with gelatin (Lifetechnologies, G13187). Fraction analysis were checked for interest proteins by Western Blot.

Proximity ligation assay (PLA). Proximity ligation assay was performed according to the manufacturer's recommendations protocol (Duolink; Sigma). Briefly, cells were prepared as for indirect immunofluorescence. Cells were incubated with indicated primary antibodies for $2 \mathrm{~h}$ at RT. After washing, samples are incubated with the respective PLA probes for $1 \mathrm{~h}$ at $37^{\circ} \mathrm{C}$, washed and then ligated for $30 \mathrm{~min}$ at $37^{\circ} \mathrm{C}$. Amplification with polymerase was then performed for $100 \mathrm{~min}$ at $37^{\circ} \mathrm{C}$ in the dark. After several washes, nuclei are stained with DAPI and samples are mounted in ProLong Gold antifade reagent. Images are captured as previously described in the indirect immunofluorescence staining section.

Mass spectrometry analysis. Proteomes from E-cadherin depleted cells (BxPC-3 shEcad) were compared to control cells (BxPC-3 shCTRL) by label free quantitative mass spectrometry analysis. $15 \mu \mathrm{g}$ of each cell lysate were loaded 
on NuPAGE 4-12\% Bis-Tris acrylamide gels (Life Technologies) to stack proteins in a single band that was stained with Imperial Blue (Thermo Fisher Scientific) and cut from the gel. Gels pieces were submitted to an in-gel trypsin digestion30. Peptides were extracted from the gel and dried under vacuum. Samples were reconstituted with $0.1 \%$ trifluoroacetic acid in $4 \%$ acetonitrile and analyzed by liquid chromatography (LC)-tandem mass spectrometry (MS/MS) using an Orbitrap Fusion Lumos Tribrid Mass Spectrometer (Thermo Electron, Bremen, Germany) both online with a nanoRSLC Ultimate 3000 chromatography system (Dionex, Sunnyvale, CA). Peptides were separated on a Thermo Scientific Acclaim PepMap RSLC C18 column $(2 \mu \mathrm{m}, 100$ A, $75 \mu \mathrm{m} \times 50 \mathrm{~cm}$ ). For peptide ionization in the EASY-Spray nanosource in front of the Orbitrap Fusion Lumos Tribrid Mass Spectrometer, spray voltage was set at $2.2 \mathrm{kV}$ and the capillary temperature at $275{ }^{\circ} \mathrm{C}$. The Orbitrap Lumos was used in data dependent mode to switch consistently between MS and MS/MS. Time between Masters Scans was set to 3 seconds. MS spectra were acquired with the Orbitrap in the range of $\mathrm{m} / \mathrm{z} 400-1600$ at a FWHM resolution of 120000 measured at $400 \mathrm{~m} / \mathrm{z}$. AGC target was set at $4.0 \mathrm{e} 5$ with a 50 ms Maximum Injection Time. For internal mass calibration the 445.120025 ions was used as lock mass. The more abundant precursor ions were selected and collision-induced dissociation fragmentation was performed in the ion trap to have maximum sensitivity and yield a maximum amount of MS/MS data. Number of precursor ions was automatically defined along run in $3 \mathrm{~s}$ windows using the "Inject Ions for All Available parallelizable time option" with a maximum injection time of $300 \mathrm{~ms}$. The signal threshold for an MS/MS event was set to 5000 counts. Charge state screening was enabled to exclude precursors with 0 and 1 charge states. Dynamic exclusion was enabled with a repeat count of 1 and duration of $60 \mathrm{~s}$.

Data Processing Protocol. Relative intensity-based label-free quantification (LFQ) was processed using the MaxLFQ algorithm from the freely available MaxQuant computational proteomics platform, version 1.6.3.4. Spectra were searched against the Human database extracted from UniProt on the 1th of September 2020 and containing 20375 entries (reviewed). The false discovery rate (FDR) at the peptide and protein levels were set to $1 \%$ and determined by searching a reverse database. For protein grouping, all proteins that cannot be distinguished based on their identified peptides were assembled into a single entry according to the MaxQuant rules. The statistical analysis was done with Perseus program (version 1.6.14.0) from the MaxQuant environment (www.maxquant.org). Quantifiable proteins were defined as those detected in above $70 \%$ of samples in one condition or more. Protein LFQ normalized intensities were base 2 logarithmized to obtain a normal distribution. Missing values were replaced using data imputation by randomly selecting from a normal distribution centred on the lower edge of the intensity values that simulates signals of low abundant proteins using default parameters (a downshift of 1.8 standard deviation and a width of 0.3 of the original distribution). To determine whether a given detected protein was specifically differential, a two-sample t-test was done using permutation-based FDR-controlled at 0.01 and employing 250 permutations. The $\mathrm{p}$ value was adjusted using a scaling factor $\mathrm{s} 0$ with a value of 0.4 . Analysis was done on biological triplicates, each run three times on mass spectrometers.

Pathway enrichment analysis. Proteins identified by mass spectrometry were analysed with Ingenuity Pathway Analysis (IPA) software to study pathway enrichment. The statistical significance of the enrichment was calculated using FDR method $(\mathrm{P}$-value $<0,05)$. Protein Z-score was calculated for each protein of the selected pathway. Z-score indicate the overall activation state.

Statistical analysis. Data are presented as the means \pm s.d for three independent experiments performed in triplicate. Comparison between the 2 conditions was made using the Mann-Witney test : $\mathrm{P}<0.05$ was considered statistically significant in all analyses and is indicated by “**** when $\mathrm{P}$ $<0.001$, “**” when $\mathrm{P}<0.01$ and "**" when $\mathrm{P}<0.05$.

\section{Conclusions}

A new surprising function of E-cadherin during cancer invasion process is demonstrate in this study. The physical involvement of E-cadherin in the formation of invadopodia demonstrates its early intervention in the tumour invasion process of PDAC.

\section{ACKNOWLEDGEMENTS}

The authors thank the Dr. Philippe Chavrier (Institut Curie) for providing helpfull advices at the beginning of the project and Dr. Sylvie Thuault (CRCM) for discussions. We thank D.Isnardon and M.Rodriguez (CRCM Microscopy platform) for support. Proteomic analyses were performed at the mass spectrometry facility of Marseille Proteomics supported by IBISA (Infrastructures Biologie Santé et Agronomie), Plateforme Technologique Aix-Marseille, Canceropôle PACA, Région Sud Provence-Alpes-Côte d'Azur, Fonds Européen de Développement Régional (FEDER) and Plan Cancer.

\section{Bibliography}

1. Gaorav P. Gupta and Joan Massagué. Cancer Metastasis: Building a Framework, nov 2006. ISSN 00928674.

2. Patricia S. Steeg. Targeting metastasis, mar 2016. ISSN 14741768.

3. Anushka Dongre and Robert A. Weinberg. New insights into the mechanisms of epithelial-mesenchymal transition and implications for cancer, feb 2019. ISSN 14710080.

4. Jing Yang, Parker Antin, Geert Berx, Cédric Blanpain, Thomas Brabletz, Marianne Bronner, Kyra Campbell, Amparo Cano, Jordi Casanova, Gerhard Christofori, Shoukat Dedhar, Rik Derynck, Heide L. Ford, Jonas Fuxe, Antonio García de Herreros, Gregory J. Goodall, Anna Katerina Hadjantonakis, Ruby J.Y. Huang, Chaya Kalcheim, Raghu Kalluri, Yibin Kang, Yeesim Khew-Goodall, Herbert Levine, Jinsong Liu, Gregory D. Longmore, Sendurai A. Mani, Joan Massagué, Roberto Mayor, David McClay, Keith E. Mostov, Donald F. Newgreen, M. Angela Nieto, Alain Puisieux, Raymond Runyan, Pierre Savagner, Ben Stanger, Marc P. Stemmler, Yoshiko Takahashi, Masatoshi Takeichi, Eric Theveneau, Jean Paul Thiery, Erik W. Thompson, Robert A. Weinberg, Elizabeth D. Williams, Jianhua Xing, Binhua P. Zhou, and Guojun Sheng. Guidelines and definitions for research on epithelial-mesenchymal transition, jun 2020. ISSN 14710080.

5. Mohit Kumar Jolly, Jason A. Somarelli, Maya Sheth, Adrian Biddle, Satyendra C. Tripathi, Andrew J. Armstrong, Samir M. Hanash, Sharmila A. Bapat, Annapoorni Rangarajan, and Herbert Levine. Hybrid epithelial/mesenchymal phenotypes promote metastasis and therapy resistance across carcinomas, feb 2019. ISSN 1879016X.

6. Cornelia Kröger, Alexander Afeyan, Jasmin Mraz, Elinor Ng Eaton, Ferenc Reinhardt, Yevgenia L. Khodor, Prathapan Thiru, Brian Bierie, Xin Ye, Christopher B. Burge, and Robert A. Weinberg. Acquisition of a hybrid $\mathrm{E} / \mathrm{M}$ state is essential for tumorigenicity of basal breast cancer cells. Proceedings of the National Academy of Sciences of the United States of America, 116(15):7353-7362, apr 2019. ISSN 10916490. doi: 10.1073/pnas.1812876116. 
bioRxiv preprint doi: https://doi.org/10.1101/2020.10.09.332783; this version posted October 9, 2020. The copyright holder for this preprint (which was not certified by peer review) is the author/funder, who has granted bioRxiv a license to display the preprint in perpetuity. It is made available under aCC-BY-NC-ND 4.0 International license.

7. levgenia Pastushenko, Audrey Brisebarre, Alejandro Sifrim, Marco Fioramonti, Tatiana Revenco, Soufiane Boumahdi, Alexandra Van Keymeulen, Daniel Brown, Virginie Moers, Sophie Lemaire, Sarah De Clercq, Esmeralda Minguijón, Cédric Balsat, Youri Sokolow, Christine Dubois, Florian De Cock, Samuel Scozzaro, Federico Sopena, Angel Lanas, Nicky D'haene, Isabelle Salmon, Jean Christophe Marine, Thierry Voet, Panagiota A Sotiropoulou, and Cédric Blanpain. Identification of the tumour transition states occurring during EMT. Nature, 556(7702), 2018. ISSN 14764687. doi: 10.1038/s41586-018-0040-3.

8. Nicole M. Aiello, Ravikanth Maddipati, Robert J. Norgard, David Balli, Jinyang Li, Salina Yuan, Taiji Yamazoe, Taylor Black, Amine Sahmoud, Emma E. Furth, Dafna Bar-Sagi, and Ben Z. Stanger. EMT Subtype Influences Epithelial Plasticity and Mode of Cell Migration. Developmental Cell, 45(6):681-695.e4, jun 2018. ISSN 18781551. doi: 10.1016/j.devcel. 2018.05.027.

9. Masao Saitoh. JB special review-cellular plasticity in epithelial homeostasis and diseases: Involvement of partial EMT in cancer progression. Journal of Biochemistry, 164(4):257-264, oct 2018. ISSN 17562651. doi: 10.1093/jb/mvy047.

10. Francesca Andriani, Giulia Bertolini, Federica Facchinetti, Erika Baldoli, Massimo Moro, Patrizia Casalini, Roberto Caserini, Massimo Milione, Giorgia Leone, Giuseppe Pelosi, Ugo Pastorino, Gabriella Sozzi, and Luca Roz. Conversion to stem-cell state in response to microenvironmental cues is regulated by balance between epithelial and mesenchymal features in lung cancer cells. Molecular Oncology, 10(2):253-271, feb 2016. ISSN 18780261. doi: 10.1016/j.molonc.2015.10.002.

11. W. James Nelson, Daniel J. Dickinson, and William I. Weis. Roles of cadherins and catenins in cell-cell adhesion and epithelial cell polarity. In Progress in Molecular Biology and Translational Science, volume 116, pages 3-23. Elsevier B.V., 2013. ISBN 9780123943118. doi: 10.1016/B978-0-12-394311-8.00001-7.

12. Carien M. Niessen, Deborah Leckband, and Alpha S. Yap. Tissue organization by cadherin adhesion molecules: Dynamic Molecular and Cellular Mechanisms of Morphogenetic Regulation. Physiological Reviews, 91(2):691-731, apr 2011. ISSN 00319333. doi: 10.1152/physrev.00004.2010.

13. Jean Paul Thiery, Hervé Acloque, Ruby Y.J. Huang, and M. Angela Nieto. EpithelialMesenchymal Transitions in Development and Disease, nov 2009. ISSN 00928674

14. Andrew Sulaiman, Zemin Yao, and Lisheng Wang. Re-evaluating the role of epithelialmesenchymal-transition in cancer progression, 2018. ISSN 16748301.

15. Michele Sommariva and Nicoletta Gagliano. E-Cadherin in Pancreatic Ductal Adenocarcinoma: A Multifaceted Actor during EMT, apr 2020. ISSN 20734409.

16. Aaron P. Putzke, Aviva P. Ventura, Alexander M. Bailey, Canan Akture, John Opoku-Ansah, Müge Çeliktaş, Michael S. Hwang, Douglas S. Darling, Ilsa M. Coleman, Peter S. Nelson, Holly M. Nguyen, Eva Corey, Muneesh Tewari, Colm Morrissey, Robert L. Vessella, and Beatrice S. Knudsen. Metastatic progression of prostate cancer and E-cadherin: Regulation by ZEB1 and Src family kinases. American Journal of Pathology, 179(1):400-410, jul 2011. ISSN 00029440. doi: 10.1016/j.ajpath.2011.03.028.

17. Pradeep Reddy, Lian Liu, Chong Ren, Peter Lindgren, Karin Boman, Yan Shen, Eva Lundin, Ulrika Ottander, Miia Rytinki, and Kui Liu. Formation of E-cadherin-mediated cell-cell adhesion activates akt and mitogen activated protein kinase via phosphatidylinositol $3 \mathrm{ki}-$ nase and ligand-independent activation of epidermal growth factor receptor in ovarian cancer cells. Molecular Endocrinology, 19(10):2564-2578, oct 2005. ISSN 08888809. doi: 10.1210/me.2004-0342.

18. Laura J. Lewis-Tuffin, Fausto Rodriguez, Caterina Giannini, Bernd Scheithauer, Brian M. Necela, Jann N. Sarkaria, and Panos Z. Anastasiadis. Misregulated E-Cadherin Expression Associated with an Aggressive Brain Tumor Phenotype. PLOS ONE, 5(10):e13665, oct 2010. ISSN 1932-6203. doi: 10.1371/journal.pone.0013665.

19. Veena Padmanaban, Ilona Krol, Yasir Suhail, Barbara M. Szczerba, Nicola Aceto, Joel S. Bader, and Andrew J. Ewald. E-cadherin is required for metastasis in multiple models of breast cancer. Nature, 573(7774):439-444, sep 2019. ISSN 14764687. doi: 10.1038/ s41586-019-1526-3.

20. Lola Rahib, Benjamin D. Smith, Rhonda Aizenberg, Allison B. Rosenzweig, Julie M. Fleshman, and Lynn M. Matrisian. Projecting cancer incidence and deaths to 2030: The unexpected burden of thyroid, liver, and pancreas cancers in the united states, jun 2014. ISSN 15387445

21. Jorg Kleeff, Murray Korc, Minoti Apte, Carlo La Vecchia, Colin D. Johnson, Andrew V. Biankin, Rachel E. Neale, Margaret Tempero, David A. Tuveson, Ralph H. Hruban, and John P. Neoptolemos. Pancreatic cancer. Nature Reviews Disease Primers, 2(1):1-22, apr 2016. ISSN 2056676X. doi: 10.1038/nrdp.2016.22.

22. Andrew D. Rhim, Emily T. Mirek, Nicole M. Aiello, Anirban Maitra, Jennifer M. Bailey, Florencia McAllister, Maximilian Reichert, Gregory L. Beatty, Anil K. Rustgi, Robert H. Vonderheide, Steven D. Leach, and Ben Z. Stanger. EMT and dissemination precede pancreatic tumor formation. Cell, 148(1-2):349-361, jan 2012. ISSN 00928674. doi: 10.1016/j.cell.2011.11.025.

23. Nicoletta Gagliano, Giuseppe Celesti, Lorenza Tacchini, Stefano Pluchino, Chiarella Sforza, Marco Rasile, Vincenza Valerio, Luigi Laghi, Vincenzo Conte, and Patrizia Procacci. Epithelial-to-mesenchymal transition in pancreatic ductal adenocarcinoma: Characterization in a 3D-cell culture model. World Journal of Gastroenterology, 22(18):4466-4483, may 2016. ISSN 22192840. doi: 10.3748/wjg.v22.i18.4466.

24. Carole Siret, Aurélie Dobric, Anna Martirosyan, Chloé Terciolo, Sébastien Germain, Renaté Bonier, Thassadite Dirami, Nelson Dusetti, Richard Tomasini, Marion Rubis, Stéphane Garcia, Juan lovanna, Dominique Lombardo, Véronique Rigot, and Frédéric André. Cadherin-1 and cadherin-3 cooperation determines the aggressiveness of pancreatic ductal adenocarcinoma. British Journal of Cancer, 118(4):546-557, feb 2018. ISSN 15321827. doi: 10.1038/bjc.2017.411

25. Rémy Nicolle, Yuna Blum, Pauline Duconseil, Charles Vanbrugghe, Nicolas Brandone, Flora Poizat, Julie Roques, Martin Bigonnet, Odile Gayet, Marion Rubis, Nabila Elarouci, Lucile Armenoult, Mira Ayadi, Aurélien de Reyniès, Marc Giovannini, Philippe Grandval, Stephane Garcia, Cindy Canivet, Jérôme Cros, Barbara Bournet, Vincent Moutardier, Marine Gilabert, Juan lovanna, Nelson Dusetti, and Louis Buscail. Establishment of a pancreatic adenocarcinoma molecular gradient (PAMG) that predicts the clinical outcome of pancreatic cancer. EBioMedicine, 57, jul 2020. ISSN 23523964. doi: 10.1016/j.ebiom.2020.102858.
26. Natalia Juiz, Abdessamad Elkaoutari, Martin Bigonnet, Odile Gayet, Julie Roques, Rémy Nicolle, Juan lovanna, and Nelson Dusetti. Basal-like and classical cells coexist in pancreatic cancer revealed by single-cell analysis on biopsy-derived pancreatic cancer organoids from the classical subtype. The FASEB Journal, 34(9):12214-12228, sep 2020. ISSN 0892-6638. doi: 10.1096/fj.202000363RR.

27. Stefan Linder. MT1-MMP: Endosomal delivery drives breast cancer metastasis, oct 2015. ISSN 15408140

28. Antonio Castro-Castro, Valentina Marchesin, Pedro Monteiro, Catalina Lodillinsky, Carine Rossé, and Philippe Chavrier. Cellular and Molecular Mechanisms of MT1-MMP-Dependent Cancer Cell Invasion, oct 2016. ISSN 15308995.

29. Andrea Dalle Vedove, Federico Falchi, Stefano Donini, Aurelie Dobric, Sebastien Germain, Giovanni Paolo Di Martino, Tommaso Prosdocimi, Chiara Vettraino, Archimede Torretta, Andrea Cavalli, Veronique Rigot, Frederic André, and Emilio Parisini. Structure-based virtua screening allows the identification of efficient modulators of E-cadherin-mediated cell-cell adhesion. International Journal of Molecular Sciences, 20(14), jul 2019. ISSN 14220067. doi: 10.3390/ijms20143404.

30. Xinzi Yu, Tobias Zech, Laura McDonald, Esther Garcia Gonzalez, Ang Li, lain Macpherson, Juliane P. Schwarz, Heather Spence, Kinga Futó, Paul Timpson, Colin Nixon, Yafeng Ma, Ines M. Anton, Balázs Visegrády, Robert H. Insall, Karin Oien, Karen Blyth, Jim C. Norman, and Laura M. Machesky. N-WASP coordinates the delivery and F-actin-mediated capture of MT1-MMP at invasive pseudopods. Journal of Cell Biology, 199(3):527-544, oct 2012. ISSN 00219525. doi: 10.1083/jcb.201203025.

31. Lena Brüser and Sven Bogdan. Adherens junctions on the move-membrane trafficking of E-cadherin. Cold Spring Harbor Perspectives in Biology, 9(3), mar 2017. ISSN 19430264 doi: 10.1101/cshperspect.a029140.

32. Chloé Terciolo, Aurélie Dobric, Mehdi Ouaissi, Carole Siret, Gilles Breuzard, Françoise Silvy, Bastien Marchiori, Sébastien Germain, Renaté Bonier, Adel Hama, Roisin Owens, Dominique Lombardo, Véronique Rigot, and Frédéric André. Saccharomyces boulardii CNCM I-745 Restores intestinal Barrier Integrity by Regulation of E-cadherin Recycling. Journal of Crohn's \& colitis, 11(8):999-1010, aug 2017. ISSN 18764479. doi: 10.1093/ecco-jcc/jjx030.

33. Mohit Kumar Jolly, Marcelo Boareto, Bin Huang, Dongya Jia, Mingyang Lu, Jose' N. Onuchic, Herbert Levine, and Eshel Ben-Jacob. Implications of the hybrid epithelial/mesenchymal phenotype in metastasis. Frontiers in Oncology, 5(JUN):155, jul 2015. ISSN 2234943X. doi: 10.3389/fonc.2015.00155.

34. Feng Ding, Shuang Zhang, Shaoyang Gao, Jian Shang, Yanxia Li, Ning Cui, and Qiu Zhao. MRGBP as a potential biomarker for the malignancy of pancreatic ductal adenocarcinoma. Oncotarget, 8(38):64224-64236, 2017. ISSN 19492553. doi: 10.18632/oncotarget.19451.

35. Minhong Shen and Yibin Kang. Role Reversal: A Pro-metastatic Function of E-Cadherin Developmental Cell, 51(4):417-419, nov 2019. ISSN 15345807. doi: 10.1016/j.devcel.2019. 10.028 .

36. Maximilian Reichert, Basil Bakir, Leticia Moreira, Jason R. Pitarresi, Karin Feldmann Lauren Simon, Kensuke Suzuki, Ravikanth Maddipati, Andrew D. Rhim, Anna M. Schlitter, Mark Kriegsmann, Wilko Weichert, Matthias Wirth, Kathleen Schuck, Günter Schneider, Dieter Saur, Albert B. Reynolds, Andres J. Klein-Szanto, Burcin Pehlivanoglu, Bahar Memis, N. Volkan Adsay, and Anil K. Rustgi. Regulation of Epithelial Plasticity Determines Metastatic Organotropism in Pancreatic Cancer. Developmental Cell, 45(6):696-711.e8, jun 2018. ISSN 18781551. doi: 10.1016/j.devcel.2018.05.025.

37. Alissa M. Weaver. Invadopodia: Specialized cell structures for cancer invasion, apr 2006 ISSN 02620898

38. Elyse K. Paterson and Sara A. Courtneidge. Invadosomes are coming: new insights into function and disease relevance, jan 2018. ISSN 17424658

39. Hideki Yamaguchi. Pathological roles of invadopodia in cancer invasion and metastasis, nov 2012. ISSN 01719335

40. Elisabeth Génot and Bojana Gligorijevic. Invadosomes in their natural habitat, oct 2014 ISSN 16181298.

41. Yu Chuan Chen, Matthew Baik, Joshua T. Byers, Kathryn T. Chen, Samuel W. French, and Begoña Díaz. TKS5-positive invadopodia-like structures in human tumor surgical specimens. Experimental and Molecular Pathology, 106:17-26, feb 2019. ISSN 10960945. doi: 10.1016/j.yexmp.2018.11.005.

42. Tomer Meirson and Hava Gil-Henn. Targeting invadopodia for blocking breast cancer metastasis. Drug Resistance Updates, 39:1-17, jul 2018. ISSN 15322084. doi: 10.1016/j.drup. 2018.05.002.

43. Bassil Dekky, Michael Ruff, Dominique Bonnier, Vincent Legagneux, and Nathalie Théret. Proteomic screening identifies the zonula occludens protein ZO-1 as a new partner for ADAM12 in invadopodia-like structures. Oncotarget, 9(30):21366-21382, apr 2018. ISSN 19492553. doi: 10.18632/oncotarget.25106.

44. Damien Planchon, Eduardo Rios Morris, Mallory Genest, Franck Comunale, Sophie Vacher, Ivan Bièche, Evgeny V. Denisov, Lubov A. Tashireva, Vladimir M. Perelmuter, Stefan Linder, Philippe Chavrier, Stéphane Bodin, and Cécile Gauthier-Rouvière. MT1-MMP targeting to endolysosomes is mediated by upregulation of flotillins. Journal of Cell Science, 131(17), sep 2018. ISSN 14779137. doi: 10.1242/jcs.218925.

45. Nandan G. Pandit, Wenxiang Cao, Jeffrey Bibeau, Eric M. Johnson-Chavarria, Edwin W. Taylor, Thomas D. Pollard, and Enrique M. De La Cruz. Force and phosphate release from Arp2/3 complex promote dissociation of actin filament branches. Proceedings of the National Academy of Sciences of the United States of America, 117(24):13519-13528, jun 2020. ISSN 10916490. doi: 10.1073/pnas.1911183117.

46. Matthias Krause and Alexis Gautreau. Steering cell migration: Lamellipodium dynamics and the regulation of directional persistence, 2014. ISSN 14710080.

47. Pedro Monteiro, Carine Rossé, Antonio Castro-Castro, Marie Irondelle, Emilie Lagoutte, Perrine Paul-Gilloteaux, Claire Desnos, Etienne Formstecher, Franois Darchen, David Perrais, Alexis Gautreau, Maud Hertzog, and Philippe Chavrier. Endosomal WASH and exocys complexes control exocytosis of MT1-MMP at invadopodia. Journal of Cell Biology, 203(6): 1063-1079, dec 2013. ISSN 15408140. doi: 10.1083/jcb.201306162.

48. Thomas Brabletz, Raghu Kalluri, M. Angela Nieto, and Robert A. Weinberg. EMT in cancer, jan 2018. ISSN 14741768.

49. Catherine Fabre, Assou El Battari, Catherine Bellan, Eric Pasqualini, Jacques Marvaldi, 
bioRxiv preprint doi: https://doi.org/10.1101/2020.10.09.332783; this version posted October 9, 2020. The copyright holder for this preprint

(which was not certified by peer review) is the author/funder, who has granted bioRxiv a license to display the preprint in perpetuity. It is made available under aCC-BY-NC-ND 4.0 International license.

Dominique Lombardo, and José Luis. Characterization of the oligosaccharide moiety of VIP receptor from the human pancreatic cell line BxPC-3. Peptides, 14(6):1331-1338, nov 1993. ISSN 01969781. doi: 10.1016/0196-9781(93)90194-L.

50. Michaela R. Hoffmeyer, Kristin M. Wall, and Suranganie F. Dharmawardhane. In vitro analysis of the invasive phenotype of SUM 149, an inflammatory breast cancer cell line. Cancer Cell International, 5(1):11, apr 2005. ISSN 14752867. doi: 10.1186/1475-2867-5-11.

51. Emmanuelle Martinez, Isabelle Crenon, Françoise Silvy, Jean Del Grande, Alice Mougel, Dolores Barea, Frederic Fina, Jean Paul Bernard, Mehdi Ouaissi, Dominique Lombardo, and Eric Mas. Expression of truncated bile salt-dependent lipase variant in pancreatic pre-neoplastic lesions. Oncotarget, 8(1):536-551, 2017. ISSN 19492553. doi: 10.18632/oncotarget.11777.

52. Francesca Attanasio, Giusi Caldieri, Giada Giacchetti, Remco van Horssen, Bé Wieringa, and Roberto Buccione. Novel invadopodia components revealed by differential proteomic analysis. European Journal of Cell Biology, 90(2-3):115-127, feb 2011. ISSN 01719335. doi: 10.1016/j.ejcb.2010.05.004 
bioRxiv preprint doi: https://doi.org/10.1101/2020.10.09.332783; this version posted October 9, 2020. The copyright holder for this preprint (which was not certified by peer review) is the author/funder, who has granted bioRxiv a license to display the preprint in perpetuity. It is made available under aCC-BY-NC-ND 4.0 International license.

\begin{tabular}{|c|c|c|c|c|c|c|}
\hline Antigen & Species & Company & Reference & IF & WB & IHC \\
\hline $\begin{array}{l}\text { E-cadherin } \\
\text { [M168] }\end{array}$ & Mouse & Abcam & ab76055 & $1 / 200$ & & \\
\hline $\begin{array}{l}\text { E-cadherin } \\
\text { [24E10] }\end{array}$ & Rabbit & Cell Signaling & $3195 S$ & $1 / 100$ & & \\
\hline $\begin{array}{c}\text { E-cadherin } \\
\text { [Hecd-1] }\end{array}$ & Mouse & Abcam & ab1416 & & o0 & \\
\hline $\begin{array}{l}\text { E-cadherin } \\
\text { EP700Y }\end{array}$ & Rabbit & Abcam & $a b 40772$ & $1 / 400$ & & $\begin{array}{l}\text { Frozen: } \\
1 / 200\end{array}$ \\
\hline E-cadherin & Goat & $\begin{array}{l}\text { St John's } \\
\text { Laborarory }\end{array}$ & STJ140099 & & & $\begin{array}{l}\text { Paraffin: } \\
1 / 800\end{array}$ \\
\hline P-cadherin & Rabbit & Cell Signaling & $2130 S$ & $1 / 50$ & & \\
\hline $\begin{array}{c}\text { Cortactin } \\
\text { p80/85 [4F11] }\end{array}$ & Mouse & Millipore & $05-180$ & $1 / 200$ & .000 & $\begin{array}{c}\text { Frozen: } \\
1 / 200 \\
\text { Paraffin: } \\
1 / 200\end{array}$ \\
\hline $\begin{array}{c}\text { SH3PXD2A } \\
\text { (Tks5) }\end{array}$ & Rabbit & Novus & NBP1-90454 & $1 / 100$ & 000 & $\begin{array}{c}\text { Frozen: } \\
1 / 50 \\
\text { Paraffin: } \\
1 / 400\end{array}$ \\
\hline $\begin{array}{l}\text { MT1-MMP } \\
\text { LEM-2/15.8 }\end{array}$ & Mouse & Millipore & MAB3328 & $1 / 100$ & 00 & \\
\hline $\begin{array}{c}\text { Arp3 } \\
\text { [EPR110429] }\end{array}$ & Rabbit & Abcam & ab181164 & $1 / 400$ & $1 / 2000$ & \\
\hline Rab7 (D95F2) & Rabbit & Cell Signaling & $9367 \mathrm{~S}$ & $1 / 50$ & $1 / 1000$ & \\
\hline Rab11 & Rabbit & $\begin{array}{c}\text { Life } \\
\text { Technologies }\end{array}$ & 715300 & $1 / 50$ & .000 & \\
\hline $\begin{array}{c}\text { Actine } \\
\text { phalloïdine- } \\
\text { rhodamine }\end{array}$ & & $\begin{array}{c}\text { Life } \\
\text { Technologies }\end{array}$ & R415 & $1 / 1000$ & & \\
\hline $\begin{array}{c}\text { Anti-Mouse } \\
\text { AlexaFluor594 }\end{array}$ & Goat & Invitrogen & A11005 & $1 / 800$ & & $1 / 800$ \\
\hline $\begin{array}{c}\text { Anti-Rabbit } \\
\text { AlexaFluor594 }\end{array}$ & Goat & Invitrogen & A11072 & $1 / 800$ & & $1 / 800$ \\
\hline $\begin{array}{c}\text { Anti-Mouse } \\
\text { AlexaFluor647 }\end{array}$ & Donkey & Invitrogen & A31571 & $1 / 800$ & & $1 / 800$ \\
\hline $\begin{array}{c}\text { Anti-Rabbit } \\
\text { AlexaFluor647 }\end{array}$ & Donkey & Invitrogen & A31573 & $1 / 800$ & & $1 / 800$ \\
\hline $\begin{array}{l}\text { Anti-Goat } \\
\text { Alexa } 488\end{array}$ & Donkey & Invitrogen & A11055 & $1 / 800$ & & $1 / 800$ \\
\hline
\end{tabular}

\begin{tabular}{|c|c|c|}
\hline Reagents & Company & Reference \\
\hline FITC-Gelatin & Life Technologies & G13187 \\
\hline LipoRNAiMax & Life Technologies & P/N 56531 \\
\hline Prolong Gold & Invitrogen & P36934 \\
\hline Sodium Borohydride & Sigma & $213462-25 G$ \\
\hline Protein G Agarose & Roche & 11719416001 \\
\hline $\begin{array}{l}\text { Duolink in situ probe } \\
\text { anti-Rb PLUS }\end{array}$ & Sigma & DU092002 \\
\hline $\begin{array}{l}\text { Duolink in situ probe } \\
\text { anti-Ms MINUS }\end{array}$ & Sigma & DU092004 \\
\hline $\begin{array}{l}\text { Duolink in situ detect } \\
\text { reagent RED }\end{array}$ & Sigma & DU092008 \\
\hline Dynasore & Sigma & \\
\hline AS09 & Vitasmlab & 5914594 \\
\hline AS11 & Vitasmlab & 295928 \\
\hline
\end{tabular}

Table 1 - Antibodies and Reagents. 


\begin{tabular}{|c|c|c|c|}
\hline Target & Company & References & $\begin{array}{c}\text { Concentration } \\
\text { used }\end{array}$ \\
\hline $\begin{array}{c}\text { ON- } \\
\text { TARGETplus } \\
\text { SMARTPOOL } \\
\text { Human } \\
\text { Control }\end{array}$ & Dharmacon & $\begin{array}{c}\text { D-001810-10- } \\
05\end{array}$ & 25 or $50 \mathrm{nM}$ \\
\hline $\begin{array}{c}\text { ON- } \\
\text { TARGETplus } \\
\text { SMARTPOOL } \\
\text { Human MT1- } \\
\text { MMP } \\
\end{array}$ & Dharmacon & $\begin{array}{c}\text { L-004145-00- } \\
0005\end{array}$ & 25 or $50 \mathrm{nM}$ \\
\hline $\begin{array}{c}\text { ON- } \\
\text { TARGETplus } \\
\text { SMARTPOOL } \\
\text { Human Arp3 }\end{array}$ & Dharmacon & $\begin{array}{c}\text { L-012077-00- } \\
0005\end{array}$ & $25 \mathrm{nM}$ \\
\hline $\begin{array}{c}\text { ON- } \\
\text { TARGETplus } \\
\text { SMARTPOOL } \\
\text { Human } \\
\text { RAB7A (7879) }\end{array}$ & Dharmacon & $\begin{array}{c}\text { L-010388-00- } \\
0005\end{array}$ & $25 n M$ \\
\hline $\begin{array}{c}\text { ON- } \\
\text { TARGETplus } \\
\text { SMARTPOOL } \\
\text { Human } \\
\text { RAB11A } \\
(8766) \\
\end{array}$ & Dharmacon & $\begin{array}{c}\text { L-004726-00- } \\
0005\end{array}$ & $25 \mathrm{nM}$ \\
\hline
\end{tabular}

Table 2 - siRNA. 
bioRxiv preprint doi: https://doi.org/10.1101/2020.10.09.332783; this version posted October 9, 2020. The copyright holder for this preprint (which was not certified by peer review) is the author/funder, who has granted bioRxiv a license to display the preprint in perpetuity. It is made available under aCC-BY-NC-ND 4.0 International license.

A

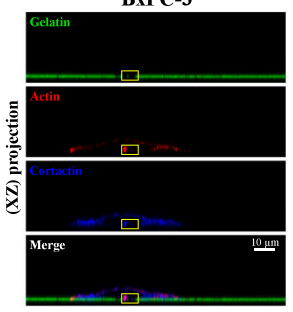

C
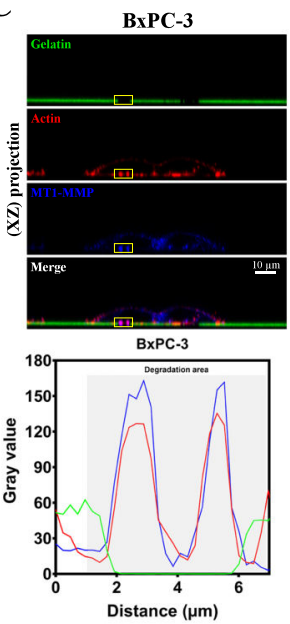

$\mathbf{E}$

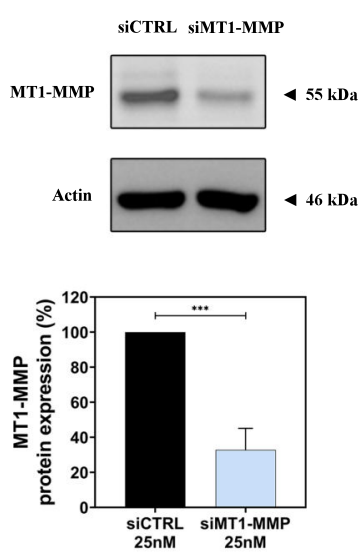

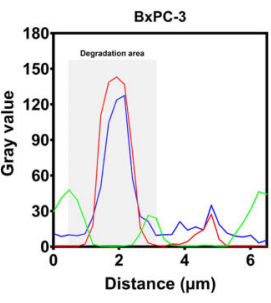

B
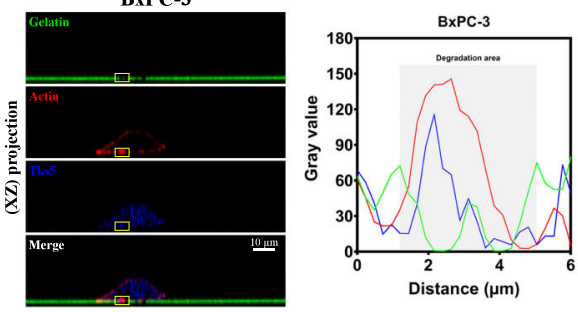

D
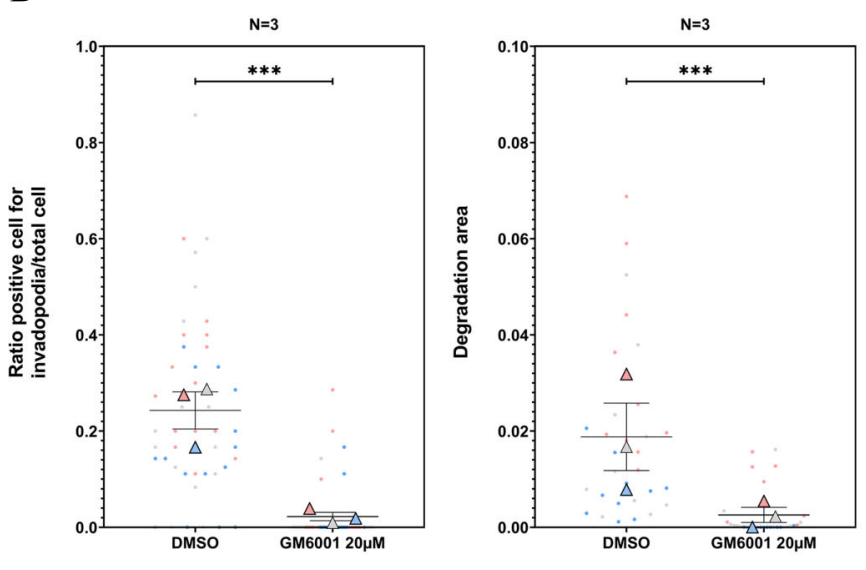

$\mathbf{F}$

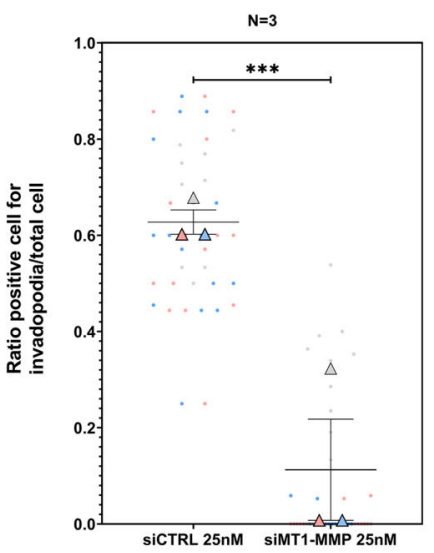

Fig. S1. (A) Actin (red) and cortactin (blue) co-staining, (B) Actin (red) and Tks5 (blue) co-staining, (C) Actin (red) and MT1-MMP (blue) co-staining in invadopodia. (A-C) BxPC-3 cells were plated for $16 \mathrm{~h}$ onto FITC-labelled gelatin. Z-stack acquisitions were performed on the fixed cells. Left panel: Co-localisation of an actin spot with a degradation zone of the gelatin (black spot) represents an active invadopodia. Scale bar $=2 \mu \mathrm{m}$. Right panel: Fluorescence intensity quantification of the ROI indicated by the yellow square on the left panel. (D) Left panel: Ratio of positive cells for active invadopodia in treated (GM6001 inhibitor) and untreated (DMSO) BxPC-3 cells. Mean from 3 independent experiments are indicated with coloured triangle. Raw data are shown with coloured dots. Experiment 1 in blue, Experiment 2 in red and Experiment 3 in grey. Errors bars represent Mean \pm SEM. Right panel: Quantification of normalized gelatin degradation area under cells for treated (GM6001 inhibitor) and untreated (DMSO) BxPC-3 cells. Means from 3 independent experiments are indicated with coloured triangle. Errors bars represent Mean \pm SEM. (E) Western Blot analysis of MT1-MMP protein expression in BxPC-3 siCTRL and siMT1-MMP cells. BxPC-3 cells were treated for 48h with siRNA control (siCTRL) or siRNA against MT1-MMP (siMT1-MMP) and plated for $16 \mathrm{~h}$ onto FITC-labelled gelatin. Equal amounts of cell lysates $(25 \mu \mathrm{g})$ were loaded on $8 \%$ polyacrylamide gels. The graph represents the Mean \pm SEM of MT1-MMP protein expression from 3 independent cell transfection. (F) Left panel: Ratio of positive cells for active invadopodia in siCTRL and siMT1-MMP cells. Mean from 3 independent experiments are indicated with coloured triangle. Raw data are shown with coloured dots. Errors bars represent Mean \pm SEM. Right panel: Quantification of normalized gelatin degradation area under cells for siCTRL or siMT1-MMP cells. Means from 3 independent experiments are indicated with coloured triangle. Errors bars represent Mean \pm SEM. 
bioRxiv preprint doi: https://doi.org/10.1101/2020.10.09.332783; this version posted October 9, 2020. The copyright holder for this preprint (which was not certified by peer review) is the author/funder, who has granted bioRxiv a license to display the preprint in perpetuity. It is made available under aCC-BY-NC-ND 4.0 International license.
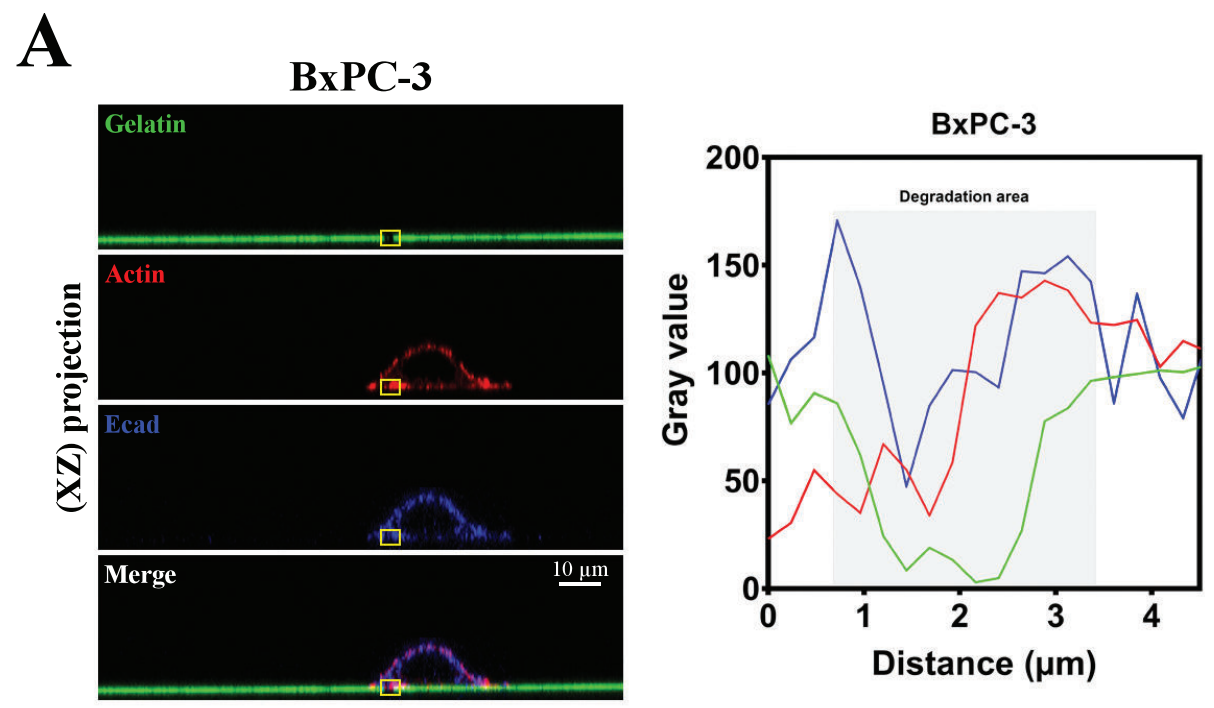

B
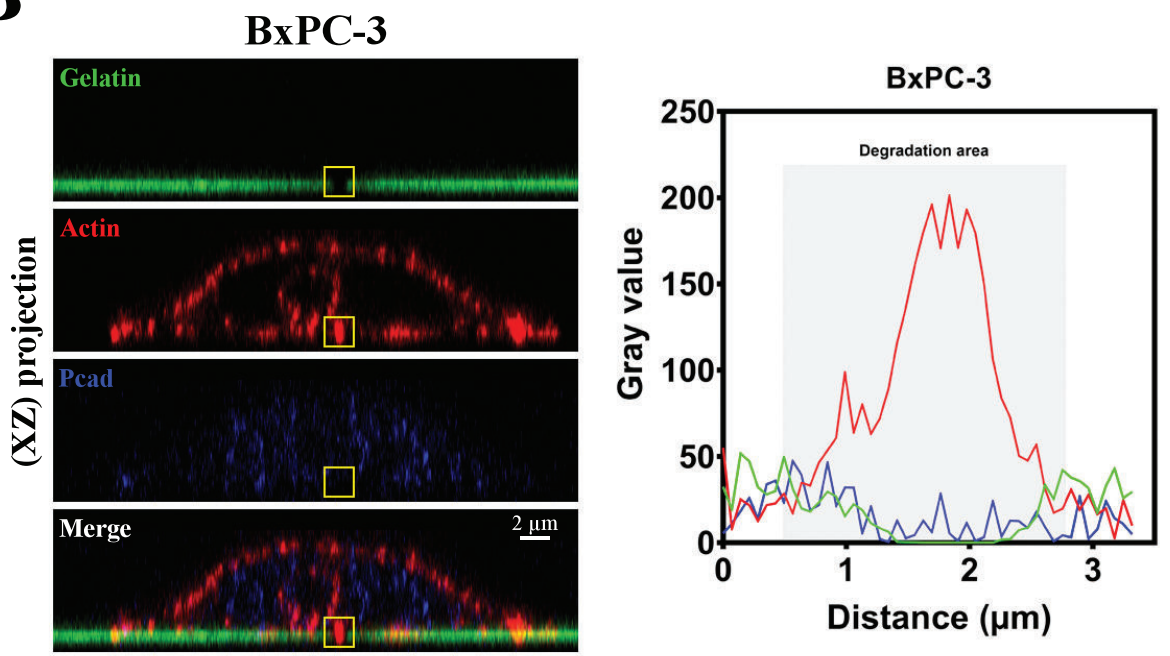

Fig. S2. (A) Actin and E-cadherin (HECD1 antibody directed to extracellular domain) co-staining (B) Actin and P-cadherin co-staining on BxPC-3 cells. A and B: BxPC-3 cell line were cultured on fluorescent gelatin. Left panel: Images represents Z-stack confocal acquisitions. Scale bar $=2 \mu \mathrm{m}$. Co-localization of an actin spot with a degradation zone of the gelatin (black spot) represents an active invadopodia. Right panel: Fluorescence intensity quantification of the ROI indicated by the yellow square on the left panel. 


\title{
Cell body Invadopodia
}

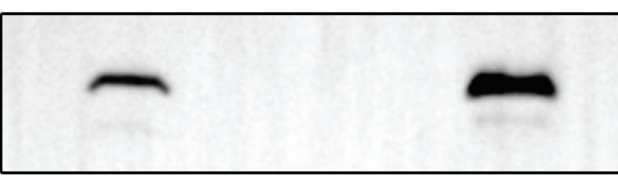

\section{$120 \mathrm{kDa}$}

MT1-MMP

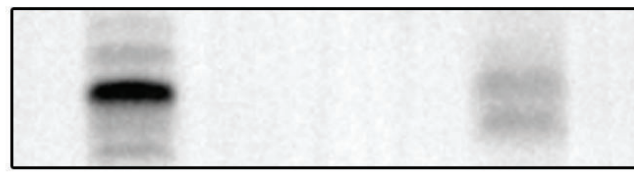

\author{
55 kDa
}

Histone H1

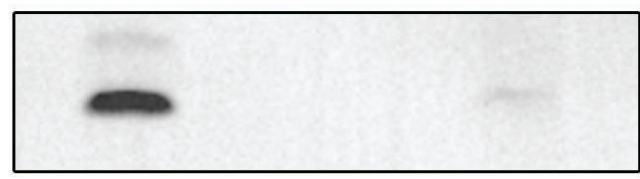

\section{3 kDa}

Fig. S3. Invadopodia fractioning analysed by Western Blot: The cell body and invadopodia membrane fraction are loading on acrylamide gel. A representative staining of each tested markers is represented on the panel.

A
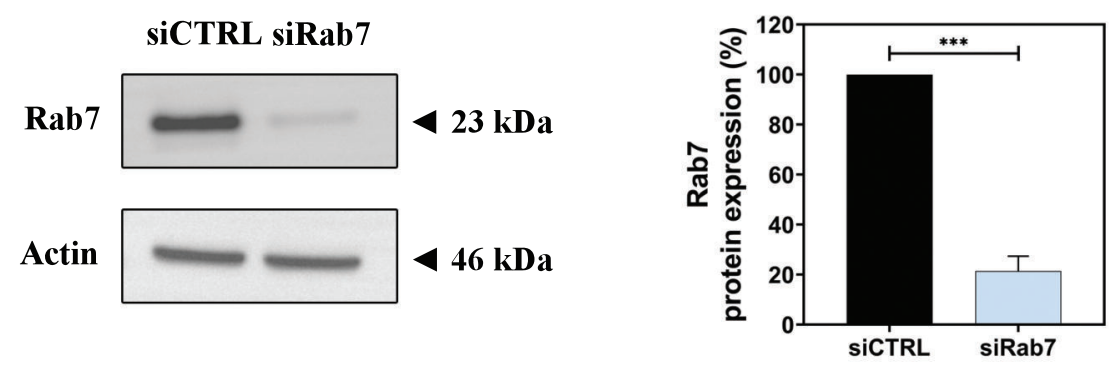

B
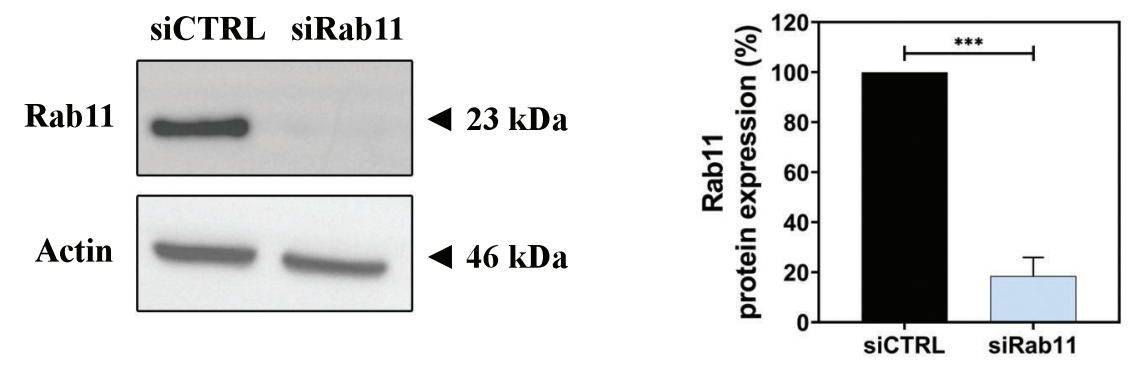

Fig. S4. (A) Western Blot analysis of Rab7 protein expression in BxPC-3 siCTRL and siRab7 cells. (B) Western Blot analysis of Rab11 protein expression in BxPC-3 siCTRL and siRab11 cells. (A-B): BxPC-3 cells were treated for 48h with siRNA (siCTRL) or siRNA against Rab7 or Rab11 and plated for 16h onto FITC-labelled gelatin. Equal amount of cell lysates $(25 \mu \mathrm{g})$ were loaded on $8 \%$ polyacrylamide gel. Graphs represent the Mean \pm SEM of Rab7 or Rab11 protein expression from 3 independent cell transfection. 